\title{
Plasma-Sprayed Hydroxylapatite-Based Coatings: Chemical, Mechanical, Microstructural, and Biomedical Properties
}

\author{
Robert B. Heimann
}

(Submitted April 26, 2016; in revised form May 10, 2016)

\begin{abstract}
This contribution discusses salient properties and functions of hydroxylapatite (HA)-based plasmasprayed coatings, including the effect on biomedical efficacy of coating thickness, phase composition and distribution, amorphicity and crystallinity, porosity and surface roughness, cohesion and adhesion, microand nano-structured surface morphology, and residual coating stresses. In addition, it will provide details of the thermal alteration that HA particles undergo in the extremely hot plasma jet that leads to dehydroxylated phases such as oxyhydroxylapatite (OHA) and oxyapatite (OA) as well as thermal decomposition products such as tri-(TCP) and tetracalcium phosphates (TTCP), and quenched phases such as amorphous calcium phosphate (ACP). The contribution will further explain the role of $\mathrm{ACP}$ during the in vitro interaction of the as-deposited coatings with simulated body fluid resembling the composition of extracellular fluid (ECF) as well as the in vivo responses of coatings to the ECF and the host tissue, respectively. Finally, it will briefly describe performance profiles required to fulfill biological functions of osteoconductive bioceramic coatings designed to improve osseointegration of hip endoprostheses and dental root implants. In large parts, the content of this contribution is a targeted review of work done by the author and his students and coworkers over the last two decades. In addition, it is considered a stepping stone toward a standard operation procedure aimed at depositing plasma-sprayed bioceramic implant coatings with optimum properties.
\end{abstract}

Keywords biomedical performance, calcium phosphates, hydroxylapatite coatings, plasma spraying, properties

\section{Introduction: A Short History of Bioceramic Materials Research}

Worldwide, development and property optimization of bioceramic materials based on hydroxylapatite (HA, $\left.\mathrm{Ca}_{10}\left(\mathrm{PO}_{4}\right)_{6}(\mathrm{OH})_{2}\right)$ are the vanguard of health-related research efforts in many countries. Arguably, research into biomaterials senso lato has reached levels of involvement and sophistication second only to electronic ceramics. The reason for this is obvious as large proportions of an aging population, predominantly in developed countries, rely increasingly on repair or replacement of body parts, or restoration of lost body functions. These functions range from artificial dental roots, alveolar ridge, iliac crest and cheek augmentation, and spinal implants to hip and knee endoprostheses.

An ever-increasing number of patients receive largejoint reconstructive hip and knee implants to repair the ambulatory knee-hip kinematic. In addition, dental, smalljoint, and spine implants are target areas of biomedical

Robert B. Heimann, Am Stadtpark 2A, 02826 Görlitz, Germany. Contact e-mail: robert.heimann@ocean-gate.de. implantology. The number of metallic, ceramic, and polymeric implants of all kinds delivered worldwide to needy patients is in the range of 10 million annually. Consequently, the global count of orthopedic surgeries increases by a whopping $10-12 \%$ per year. Presently, the worldwide sales of hip and knee orthopedic surgical joint replacement products are US\$ 16.7 billion, anticipated to reach US\$ 33 billion by 2022 (Ref 1$)$.

Calcium phosphates are of overwhelming importance to sustain life (Ref 2). It is often said that the inorganic part of bone consists of 'hydroxylapatite.' This is, however, far from the truth as bone mineral contains only about $15 \%$ of the amount of hydroxyl ions that is found in mineralogical end-member hydroxylapatite. In addition, it contains about 6 mass \% carbonate anions and about 3 mass \% water (Ref 44). Such calcium- and hydroxyl-deficient, carbonated hydroxylapatite (CHA) constitutes the inorganic component of the biocomposite materials 'bone' and 'tooth,' designed by Mother Nature to provide the mechanical strength and resilience of the gravity-defying bony skeletons of all vertebrates as well as the resistance of teeth to masticatory stresses. However, these natural biological hydroxylapatite-collagen composites provide not only strength but also flexibility. In addition, their porous structure allows exchanging essential nutrients. Bone supports biologically compatible resorption and precipitation behavior under appropriate physical and chemical conditions that closely control the build-up of bony matter by osteoblasts and its resorption by osteoclasts. Hence, bone-like, i.e., calcium-deficient defect, 
hydroxylapatite is a reservoir of phosphorus that can be delivered to the body on demand (Ref 3 ).

Concurrent with the importance of calcium phosphates for life, research into these biomaterials has a long pedigree. Almost one hundred years ago, Albee \& Morrison (Ref 4) considered calcium phosphates the materials of choice for bone regeneration, as these compounds mimic the chemical make-up of bone and tooth, which later were recognized to be biocomposites of $\mathrm{Ca}$-deficient defect hydroxylapatite ('bone-like apatite') and triple-helical strands of collagen I. About 40 years ago, researchers suggested fully crystalline synthetic hydroxylapatite as a suitably biocompatible, but essentially bioinert, material for incorporation in the human body, together with other bioinert ceramics such as high-purity alumina (Ref 5) and zirconia (Ref 6-8). This was the advent of first-generation biomaterials. In a next step, bone-like hydroxylapatite was introduced as a bioactive, i.e., bone growth-supporting (osteoconductive) material, thus constituting second-generation biomaterials. Among their first application were plasma-sprayed coatings for dental implants, followed by coatings of the stem of hip endoprostheses to improve implant integration with the surrounding bone (Ref 9). These applications are still standard today.

Endoprostheses were initially fashioned from bioinert metals such as CoCrMo alloy and austenitic surgical steels (AISI 316L, AISI 304), later from cp-Ti with enhanced corrosion resistance, followed by lower modulus $\alpha+\beta$-type Ti-based alloys such as Ti6Al4V. Eventually, Ti6Al7Nb and Ti5Al2.5Fe alloys were developed to overcome the potential cytotoxicity of V. Further developments aimed at low modulus $\beta$-type $\mathrm{Zr}$-containing alloys (Ti13Nb13Zr) and others, with elastic moduli below $50 \mathrm{GPa}$, approaching those of human cortical bone (10-30 GPa).

Subsequently, researchers realized that with the advent of second-generation biomaterials a strictly materialbased approach had reached its limits. Hence, development was continued by biologically inspired third-generation biomaterials ( Ref 10) that now concentrated on repair and regeneration of damaged or lost tissue on a molecular scale. One example is through functionalization of the surfaces of bioceramics or biopolymers by osteoinductive biological agents such as bone morphogenetic proteins (BMPs) or other non-collagenous proteins. Such proteins provide biochemical signals to bone cells that trigger their proliferation (Ref 11).

Today, innovation has been partially achieved in the following areas of tissue engineering (Ref 12):

- Development of third-generation biomaterials able to activate and sustain genetic repair mechanisms,

- Tissue engineering by molecular scaffolding,

- Stem cell engineering including marrow stem cell (MSC) therapy, and

- Rapid and highly predictive in vitro-testing techniques for biomaterial-cell response evaluation.

Stem cell engineering, still a highly contentious issue hotly debated among various segments of the population and politicians, and rapid and predictive in vitro test methods for biomaterial-cell responses that would restrict or even alleviate costly and ethically dubious animal models are fertile areas of biomaterials research and development.

In conclusion, materials intended for biomedical purposes have conceptually evolved through three different generations, comprising first-generation bioinert materials with solely mechanical and/or space-filling functions, second-generation bioactive and biodegradable materials to provide osteoconductive function, and third-generation materials designed to stimulate specific cell responses at the molecular level (Ref 13). Increasingly, computational modeling is being used for correlating gene expression profiling (genomics) with combinatorial material design strategies (materiomics). This approach adds both highthroughput capability and additional power to the analysis of biological effects induced by salient biomaterials properties (Ref 14).

Recently, Ning et al. (Ref 15) proposed the idea of fourth-generation biomaterials based on integrating electronic systems with the human body to provide powerful diagnostic as well as therapeutic tools for basic research and clinical use. The functionalities of such biomaterial systems are thought to include manipulating cellular bioelectric responses for tissue regeneration as well as monitoring cellular responses with the aim to communicate with host tissues via bioelectric signals. It is anticipated that plasma-sprayed calcium phosphates will play a commanding role in the endeavor to develop and clinically test novel fourth-generation bioceramic materials. In particular, weak electrically conducting transition metal (Ti, Zr)substituted calcium orthophosphates with $\mathrm{NaSiCON}(\mathrm{Na}$ superionic conductor) structure (Ref 16) display elevated solid-state ionic conductivity in excess of $4 \times 10^{-12} \mathrm{~S} / \mathrm{m}$ (Ref 17) that may lend itself to this task.

\section{Plasma Spray-Deposition of Hydroxylapatite Coatings: Advantages and Disadvantages}

Osteoconductive and, increasingly, osteoinductive coatings based on hydroxylapatite are still a mainstay of modern implantology. Impressive advances were achieved by applying calcium phosphates as bone-like materials for repair and replacement of diseased or missing bone, targeted delivery vehicles of drugs including photodynamic therapy, synthetic bone graft substitutes, and materials for 3D-printed scaffolds. However, as stressed by Habraken et al. in a recent review (Ref 18), these successes were overshadowed by other, apparently more modern, more sophisticated, and sometimes more speculative, developments. This perceived neglect to recognize the overriding role of calcium phosphates in implantology does not do justice to the enormous, yet still not fully exploited potential calcium phosphates possess in the area of biomineralization including coating for biomedical implants (Ref 19, 20). A recent comprehensive review 
highlights the significance of calcium phosphate coatings for de novo bone formation (Ref 21).

Among various deposition techniques, atmospheric plasma spraying (APS) was and still is the method of choice (Ref 20-24). In the past, much excellent work was performed by several research groups around the world including De Groot et al. (Ref 25), McPherson et al. (Ref 26), Gross and Berndt (Ref 27, 106), Khor et al. (Ref 28), Ding et al. (Ref 29), Lugscheider et al. (Ref 30), and others.

However, alternative techniques abound, including low-pressure (vacuum) plasma spraying (LPPS/VPS; Ref 31, 32), suspension plasma spraying (SPS; Ref 33, 34), solution precursor plasma spraying (SPPS; Ref 35), as well as microplasma (MIPS; Ref 36) and low-energy plasma spraying (LEPS; Ref 37). All these plasma-assisted deposition techniques offer a fast, well-controlled, economically advantageous, and, in its processing technology, mature way to coat almost any substrate with those materials that possess a defined congruent melting point. However, this requirement must be relaxed as hydroxylapatite melts incongruently, i.e., decomposes on melting into tricalcium $\left(\mathrm{Ca}_{3}\left(\mathrm{PO}_{4}\right)_{2}, \alpha\right.$ - and $\beta$-TCP $)$ and tetracalcium $\left(\mathrm{Ca}_{4} \mathrm{O}\left(\mathrm{PO}_{4}\right)_{2}\right.$, TTCP) phosphates, or even cytotoxic calcium oxide, $\mathrm{CaO}$ (see Table 2). Moreover, a large portion of the molten powder material solidifies, adjacent to the implant surface, by rapid quenching to form amorphous calcium phosphate (ACP) of various compositions (Ref 38, 39).

Consequently, biomedical coatings deposited by thermal spray techniques will have properties differing in chemical and phase composition, crystallinity, crystallite size, and defect density from natural bone-like apatite. Moreover, conventional APS of hydroxylapatite is unable to provide coatings with thickness below about $20 \mu \mathrm{m}$, a property that frequently does not meet medical requirements. To achieve thinner coating layers, recently suspension (SPS) and solution precursor plasma spaying (SPPS) techniques were developed. Furthermore, line-ofsight limitation makes coating of geometrically complex substrate shapes difficult, and undesirable local heating of the implant substrate may affect its metallic microstructure, as experienced, for example, by the forced $\alpha / \beta$ transition of alloyed titanium at high temperature. In addition, porosity control in the sprayed material is difficult, as plasma spraying results in rather dense coating layers (Fig. 2c). Such material is unable to satisfy biomedical needs that call for pore sizes in excess of the $75 \mu \mathrm{m}$ (Table 1) required to guarantee unimpeded ingrowth of bone cells. Indeed, deposition of dense, stoichiometric, and well-crystallized hydroxylapatite coating layers is frequently ineffective. The reason is that those coatings tend to be bioinert because they have lost their osteoconductive property based on sufficient solubility. In general, the porosity of plasma-sprayed coatings is determined by both powder particle size and the degree of particle melting that is turn is controlled by plasma gas composition, powder injection mode, and spray distance.

To attain bioactive, i.e., osteoconductive functionality, hydroxylapatite ought to have some degree of non-stoichiometry, expressed by both $\mathrm{Ca}$ deficiency caused by substitution of $\mathrm{Ca}$ cations by metabolic elements such as $\mathrm{Mg}, \mathrm{Sr}, \mathrm{Na}, \mathrm{K}$, and others, and substitution of carbonate ions for orthophosphate (type-B defect) or hydroxyl (typeA defect) anions (Ref 40, 41). In particular, it has been found that in low-temperature apatites carbonate ions prefer to substitute for phosphate (type-B substitution) rather than for (monovalent) ions in channel sites (type-A substitution) (Ref 42). Such non-stoichiometric, substituted, disordered, and sparingly soluble nano-crystalline CHA compositions closely resemble the so-called 'bonelike' biological apatite with the approximate formula $\mathrm{Ca}_{10-x}\left(\mathrm{HPO}_{4}\right)_{x}\left(\mathrm{PO}_{4}\right)_{6-x} \quad\left(\mathrm{OH}, \mathrm{O}, \mathrm{Cl}, \mathrm{F}, \mathrm{CO}_{3}, \square\right)_{2-x} \cdot n \mathrm{H}_{2} \mathrm{O}$; $0<x<1 ; 0<n<2.5$, the chemical variability of which aptly illustrates the complexity of the task at hand (Ref 43). Recently, Pasteris has pointed out similarities and differences between biological apatite and the calcium phosphate phases typically synthesized as biomaterials (Ref 44).
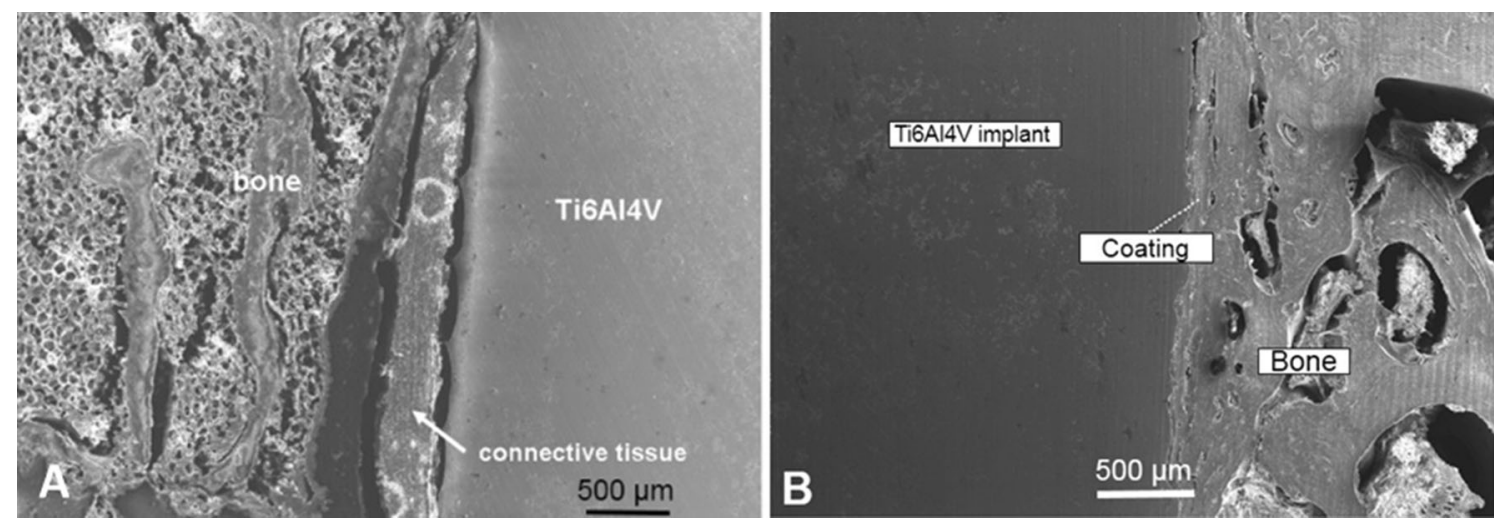

Fig. 1 The in vivo function of hydroxylapatite-based implant coatings after an implantation time of 6 months. (a) An uncoated Ti6Al4V cube $\left(5 \times 5 \times 5 \mathrm{~mm}^{3}\right)$, surgically implanted into the lateral condyle of a canine femur, shows encapsulation by a layer of connective tissue (center) separating the implant (right) from the bone (left). (b) A hydroxylapatite-coated Ti6Al4V cube $\left(5 \times 5 \times 5 \mathrm{~mm}^{3}\right)$, implanted into the lateral condyle of a canine femur, results in strong and continuous connection of implant (left) and cortical bone (right) (Ref 53, 54) 


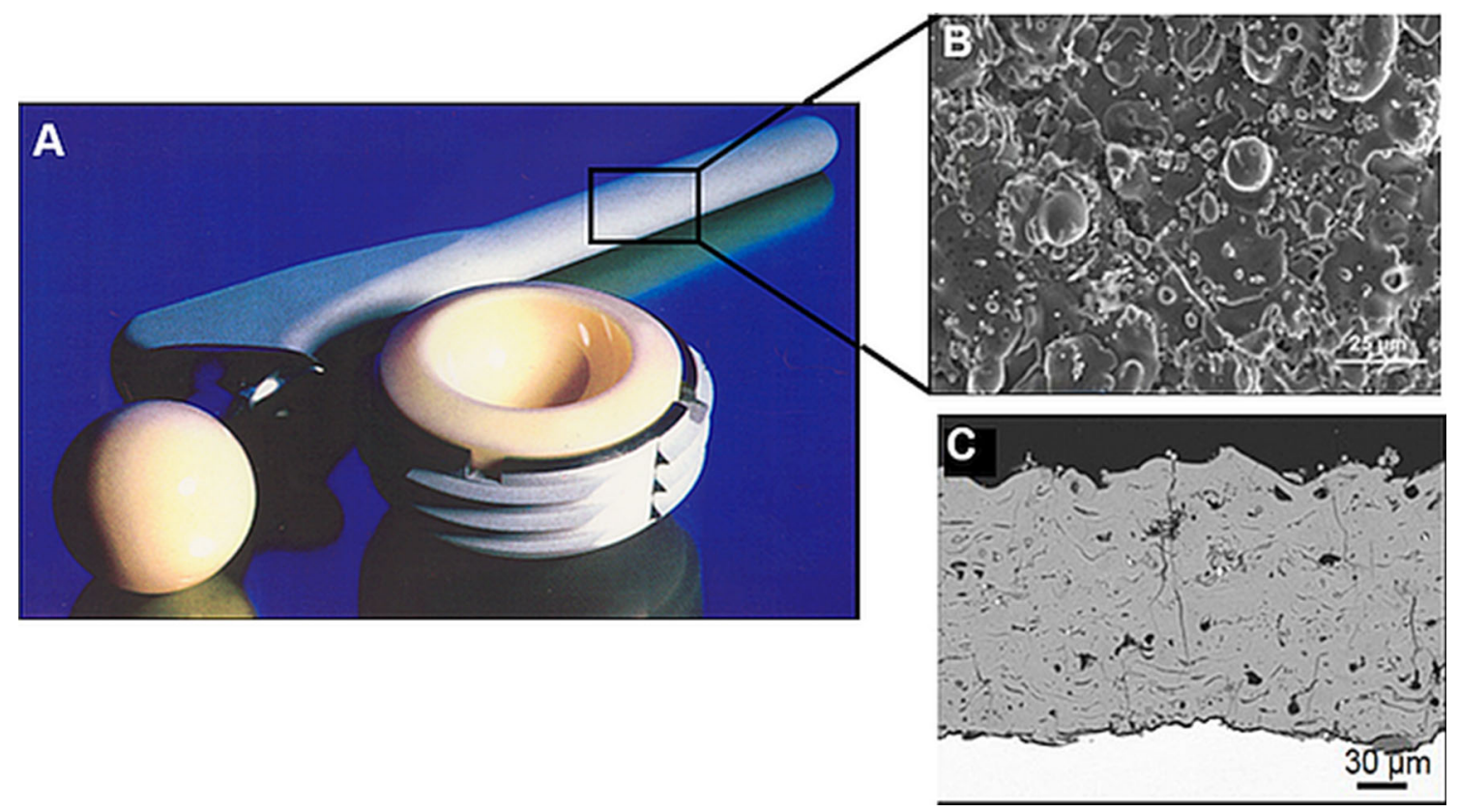

Fig. 2 (a) State-of-the-art, high-end endoprosthetic hip implant showing the HA-coated Ti6Al4V stem with an alumina femoral ball attached (left) and the likewise coated titanium acetabular cup with an alumina inset designed to actuate against the ball (right) under very low friction conditions (Image courtesy Professor Gerd Willmann $\dagger$, CeramTec AG, Plochingen, Germany). (b) Surface of a typical plasma-sprayed HA coating with well-developed pancake-like molten particle splats and some loosely adhering incompletely melted spherical particles (Ref 47). (c) Cross section of a plasma-sprayed HA coating on a Ti6Al4V substrate, showing some pores (dark patches) and radial cracks. The splat-like nature of the coating is apparent (Ref 61) (C) With permission by John Wiley and Sons)

To alleviate the disadvantages of plasma-sprayed hydroxylapatite coatings, the search is on to investigate, develop, and eventually clinically apply coatings deposited at temperatures much below the incongruent melting point of hydroxylapatite, ideally at or near ambient temperature (Ref 45). However, still post-depositional heat treatment must frequently be applied. Annealing may be required to crystallize $\mathrm{ACP}$, to transform non-apatitic hydrated precursor phases such as octacalcium phosphate $\left(\mathrm{Ca}_{8}\left(\mathrm{HPO}_{4}\right)_{2}\left(\mathrm{PO}_{4}\right)_{4} \cdot 5 \mathrm{H}_{2} \mathrm{O}, \mathrm{OCP}\right)$ or dicalcium phosphate dihydrate ( $\mathrm{CaHPO}_{4} \cdot 2 \mathrm{H}_{2} \mathrm{O}$, DCPD, brushite) to hydroxylapatite, and/or to remove residuals of organic compounds used in coating preparation, for example, during sol-gel, dip coating, electrochemical, and electrophoretic deposition processes. However, lack of sufficient adhesive and cohesive strengths of low-temperature deposited coatings remains an issue that can be remedied somewhat by applying appropriate bond coats (for example Ref 46, 47) and by adding reinforcing polymeric materials (for example Ref 48), respectively.

Notwithstanding the acknowledged shortcomings of plasma-sprayed hydroxylapatite that include thermal decomposition, line-of-sight limitation, and the inability to deposit coatings of less than about $20 \mu \mathrm{m}$ thickness, thermal spraying is still the method of choice to apply coatings to the metallic parts of commercially supplied hip and knee endoprostheses as well as dental root implants. Currently, plasma spraying of hydroxylapatite powder particles with diameters of tens to hundreds of micrometers is the most popular and the only Food and Drug
Administration (FDA)-approved method to coat implant surfaces for clinical use (Ref 49, 50).

In conclusion, even though deposition of hydroxylapatite coatings by atmospheric (air) plasma spraying comes across as a mature and well research-supported technique, there is a need to address several shortcomings. Consequently, during the past decades, many attempts have been made to optimize essential properties of osteoconductive bioceramic coatings deposited by conventional APS. These properties include coating cohesion and adhesion, phase composition, homogeneous phase distribution, crystallinity, porosity and surface roughness, nanostructured surface morphology, residual coating stress, and not in the least, coating thickness (Ref 20, 51, 52). The present contribution attempts to highlight important aspects of the quest to design hydroxylapatite-based coatings with optimum mechanical, chemical, microstructural, and biomedical properties.

\section{Advantages of Hydroxylapatite-Based Coatings}

Hydroxylapatite coatings deposited by plasma spraying onto the metallic stem of hip endoprosthetic implants (see Fig. 2) significantly reduce the time required for osseointegration and provide osteogenesis, i.e., a genuine, biochemically mediated, strong bonding without a fibrillar connective tissue capsule. Such an undesirable acellular 
connective tissue capsule frequently forms around a metallic or ceramic implant body in the absence of a bioconductive coating, impeding lasting strong and solid osseointegration (Fig. 1a). In contrast to this, Fig. 1(b) shows impressively the biomedical function of a hydroxylapatite coating that prevents the formation of a connective tissue layer, leading to strong and continuous connection between implant and bone.

Thus, hydroxylapatite coating of hip implants has been confirmed to achieve long-term survival in the human body, provided that certain requirements are met that include appropriate design selection, sound choice of bearing surfaces based on the patient's life expectancy, meticulous surgical technique, and adequate bone quality (Ref 55). Meta-analysis of twenty-one follow-up studies (Ref 56) showed that hydroxylapatite coatings could improve significantly the post-operative Harris hip score (HHS, Ref 57) over that of stems coated with porous titanium. In particular, the former were found to reduce post-operative thigh pain as well as the incidence of femoral osteolysis, whereas there was no statistical difference between the hydroxylapatite-coated and porous-coated groups in femoral stem survivorship from aseptic loosening, polyethylene wear, and radiolucent lines. Consequently, HAcoated cementless implants are still considered the current 'gold standard' in hip arthroplasty and dental restoration.

Advantages of hydroxylapatite-based coatings include (Ref 20)

- High biocompatibility

- High bioactivity

- Faster and improved osseointegration

- Absence of fibrillar connective tissue surrounding the implant

- Osseointegration possible even in the presence of patient-induced micro-motion between implant and bone

- Formation of a strong bond between implant and bone with tensile strengths between 35 and $100 \mathrm{MPa}$, depending on coating thickness

- Reduction of post-operative pain (Ref 56)

- Promotion of earlier implant loading after healing phase

- Variable metallic implant materials possible, including cp-titanium, titanium alloys (Ti6Al4V, Ti6Al7Nb, Ti24Nb4Zr8Sn), CoCrMo alloys, and surgical austenitic stainless steels (AISI 316L, AISI 304)

- Variable surface structures possible, including mesh, artificial spongiosa, beaded titanium coatings, and roughened or otherwise micro-patterned surfaces (Ref 58)

- Thickness of APS coatings can be selected between 50 and $250 \mu \mathrm{m}$, depending on application. However, novel deposition techniques such as suspension (SPS) or solution precursor plasma spraying (SPPS) allow deposition of thinner coatings below $20 \mu \mathrm{m}$.

- Rare problems with coating delamination or spalling in vivo
- Reduction or elimination of release of potentially cytotoxic metallic ions from the coated implant surface to the surrounding living tissue

- Suitable dissolution/resorption resistance in contact with body fluid

- Quality control and standard tools available according to ASTM F 1185-03 (Ref 59) as well as ISO 13485 (Ref 60) designations.

Figure 2(a) shows a state-of-the-art, high-end hip endoprosthesis with an alumina femoral ball designed to articulate against an alumina acetabular cup. This ceramic-ceramic wear couple excels by much reduced friction, a requirement necessary to counter for the lack of synovial fluid that in a healthy hip joint provides a very low friction coefficient. This synovial fluid contains high levels of hyaluronic acid that help maintain high fluid viscosity and support the normal integrity of the joint by attenuating inflammation and preserving the cartilaginous matrix covering the femoral head.

The Ti6Al4V stem of the endoprosthesis device shown in Fig. 2a has been plasma spray coated with hydroxylapatite by its manufacturer (CeramTec AG, Plochingen, Germany). The SEM micrographs depict the surface of the coating (top right, Fig. 2b) as well as its cross section (bottom right, Fig. 2c). The SEM image of the cross section of a plasma-sprayed coating (Fig. 2c) reveals a coating thickness of $160 \pm 10 \mu \mathrm{m}$ with surface roughness of $9 \pm 0.5 \mu \mathrm{m}$, low porosity of $8 \pm 1 \mathrm{vol} . \%$, pore size range between 10 and $20 \mu \mathrm{m}$, and adequate strength of adhesion to the Ti6Al4V substrate of $38 \pm 9 \mathrm{MPa}$ (Ref 93). Note that the SEM images of Fig. $2 b$ and $c$ relate to experimentally plasma-sprayed samples (Ref 47, 61, 93), but not to the actual implant stem shown in Fig. 2a. These SEM images are shown here only for the purpose of illustrating the typical micromorphology of well-designed plasmasprayed hydroxylapatite coatings.

The coating reveals stacks of flat pancake-like splats of calcium phosphate of various composition as well as some loosely adhering incompletely melted oversized particles (Fig. 2b). This feature could be potentially deleterious since only loosely adhering particles may become liberated in vivo, will be distributed by the lymphatic system throughout the body, and may subsequently trigger in susceptible patients periprosthetic inflammation and even aseptic implant loosening accompanied by osteolysis (Ref 62 ). Even more hazardous may be the presence of nanosized hydroxylapatite particles released from implant coatings that could elicit an inflammatory reaction leading eventually to implant failure. Indeed, recent research suggests that such nano-sized hydroxylapatite particles may not only induce inflammation but may also decrease the viability of primary human polymorphonuclear cells, mononuclear cells, and human dermal fibroblasts, increase apoptotic cell behavior, and display an elevated ROS (reactive oxygen species) response (Ref 63). Consequently, great care must be taken to avoid the presence of such undesirable coating features. 

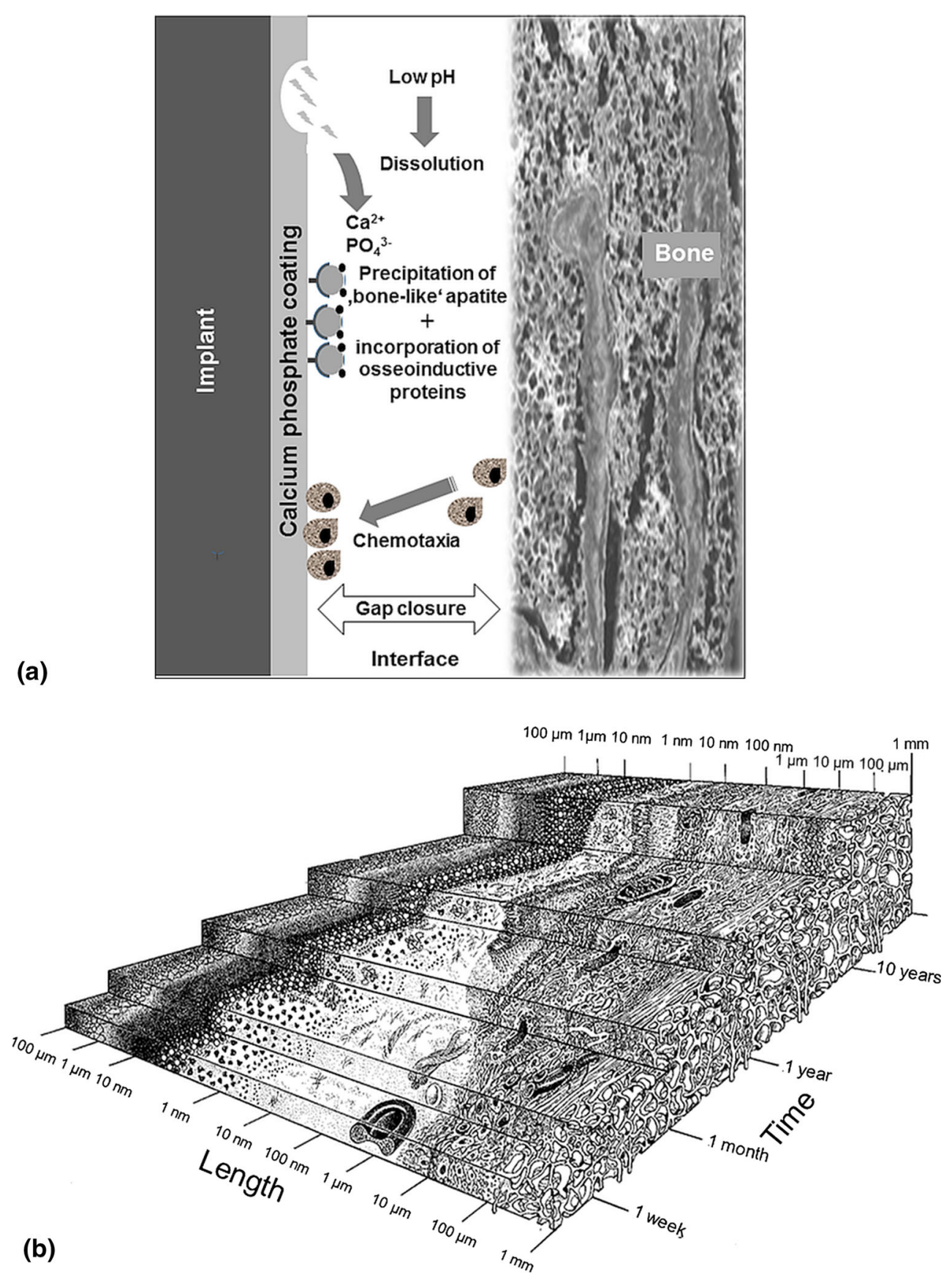

Fig. 3 (a) Schematic representation of cell-implant interaction mediated by a thin calcium phosphate coating layer (adapted from Ref 77). A local decrease of $\mathrm{pH}$ results in partial dissolution of the coatings, triggering the release of chemotactic agents from bone. Addition of $\mathrm{Ca}^{2+}$ and $\mathrm{PO}_{4}{ }^{3-}$ ions leads to increased supersaturation of the extracellular fluid (ECF) with respect to hydroxylapatite, precipitating 'bone-like' apatite and promoting subsequent incorporation of osteoinductive proteins such as osteocalcin, osteonectin, as well as annexins and integrins. (b) Schematics of implant healing in which the logarithmic length and time scales indicate the complex dynamic process of osseointegration (Ref 174) (@ With permission of University of Toronto Press)

\section{Principles of Osseointegration of Hydroxylapatite Coatings}

Before embarking on the description of technical aspects of coating deposition and the analytical procedures applied to monitor and control their application-relevant properties, salient features will be briefly outlined of the interaction of such coatings with the environment of the human body.

The bone growth-stimulating function of hydroxylapatite coatings can best be expressed by two biomedicalderived properties, termed osteoconductivity and osteoinductivity. On the one hand, osteoconductivity is the 
ability of a biomaterial to support the in-growth of bone cells, blood capillaries, and perivascular tissue into the operation-induced gap between implant body and existing (cortical) bone bed. Interconnected coating pores of 100$300 \mu \mathrm{m}$ size (Ref 64) foster the process of osseogenesis and osseointegration, thus underscoring the need to enhance and control pore sizes. Indeed, development of such pore networks in hydroxylapatite coatings is of the utmost importance since pore-free coatings that are too dense lose their bioactivity and act like bioinert materials. Hence, their eventual substitution by bone tissue is not guaranteed at all. On the other hand, the term osteoinductivity refers to the ability to transform undifferentiated mesenchymal precursor stem cells into osseoprogenitor cells that precede endochondral ossification. This process relies crucially on the osteoinductive action of non-collagenous proteins as will be discussed below.

Biocompatibility, osteoconductivity, and osteoinductivity of calcium phosphate-based bioceramic materials are generally attributed to their (i) chemical composition that resembles that of the inorganic component of natural bone, (ii) micro- or nano-structured surface topography, (iii) appropriate macro- and microporosity, (iv) enhanced bioadhesion, and (v) favorable dissolution kinetics. According to current views on calcium phosphate osseogenicity, $\mathrm{Ca}^{2+}$ and $\left[\mathrm{PO}_{4}\right]^{3-}$ ions released from dissolving hydroxylapatite coatings during interaction with body fluid profoundly affect the migration, proliferation, and differentiation of osteoblasts during bone formation. However, the exact molecular mechanisms guiding de novo bone formation are still under debate.

At a molecular scale, apatite nucleation is thought to begin with nucleation of calcium phosphate proto-nuclei (embryos) from the extracellular body fluid (ECF), which is supersaturated with respect to hydroxylapatite. Ab initio calculations suggest that the first products of precipitation involve the so-called Posner's cluster $\left\{\mathrm{Ca}_{3}\left(\mathrm{PO}_{4}\right)_{2}\right\}_{3}$ that has the energetically most favored and hence most stable configuration (Ref 65). However, it is not clear at all how the transition occurs from these clusters with $\mathrm{Ca} /$ $\mathrm{P}=1.5$ to $\mathrm{HA}$ with $\mathrm{Ca} / \mathrm{P}=1.67$, and how the presence of organic species will affect this conversion mechanism. Experimental evidence obtained by in situ synchrotron small-angle $\mathrm{x}$-ray scattering (SAXS) suggests that car- boxylate ligands such as citrate and oxalate anions delay the onset of HA nucleation, whereas non-collagenous proteins such as osteocalcin, osteonectin, and proteoglycans lead to enhanced nucleation (Ref 66). In particular, osteocalcin shows high affinity for HA and appears to play a significant role in cell signaling for bone formation (Ref 67). Moreover, octacalcium phosphate $\left(\mathrm{Ca}_{8}\left(\mathrm{HPO}_{4}\right)_{2}\right.$ $\left.\left(\mathrm{PO}_{4}\right)_{4} \cdot 5 \mathrm{H}_{2} \mathrm{O}, \mathrm{OCP}\right)$, a known precursor of hydroxylapatite nucleation, appears to support significantly enhanced appositional bone formation (Ref 68). More detailed information is beyond the scope of this review.

However, not only the precipitation kinetics but also the morphology of HA micro- or nanocrystals will be modified by structure-mediated (epitaxial) adsorption of organic constituents such as poly(amino acids) at prominent lattice planes of HA. For example, adsorption of poly(L-lysine) on $\{00.1\}$ planes causes formation of polycrystalline nanocrystals of HA, whereas adsorption of poly(L-glutamic acid) leads to precipitation of large flat micron-sized single crystals (Ref 69). Adsorption experiments involving recombinant human-like collagen (Ref 70), and citrate and cetyltrimethylammonium bromide (CTAB) (Ref 71) showed comparable relations. However, in this context it should be emphasized that aqueously precipitated carbonated, hydrated, calcium- and hydroxyldeficient apatite-like that in bone-has both the size and shape of bone crystallites, in the total absence of organics. Apparently, the carbonate incorporation suffices to control both the size and shape of crystalline apatite (Ref 175).

On a cellular level, bone mineralization is thought to originate in cell-derived microstructures called matrix vesicles by major influx of calcium and phosphate ions into the cells (Ref 72). Within the plasma membrane of the vesicles, phosphatidylserine-calcium phosphate complexes are being produced, mediated by proteins such as annexins, integrins, and the hydrolase enzyme alkaline phosphatase (ALP). These enzymes cleave phosphate groups off phosphatidylserine and thus act as foci of calcium phosphate deposition. Hence, both $\mathrm{Ca}^{2+}$ cations bound to phospholipids and $\mathrm{PO}_{4}{ }^{3-}$ anions released from the dissolving calcium phosphate biomaterial combine to nucleate ACP, which is converted to nano-crystalline hydroxylapatite (n-HA) at the vesicle membrane (Ref 73).

Table 1 Performance profile of plasma-sprayed hydroxylapatite coatings (Ref 78-80)

\begin{tabular}{|c|c|c|c|c|}
\hline Property & $\begin{array}{c}\text { Callahan et al. } \\
\text { (Ref 78) }\end{array}$ & $\begin{array}{c}\text { Wintermantel } \\
\text { and Ha (Ref 79) }\end{array}$ & $\begin{array}{c}\text { ISO 13779-2 } \\
\text { (Ref 80) }\end{array}$ & Function \\
\hline \multirow[t]{2}{*}{ Thickness $(\mu \mathrm{m})$} & & $<50$ & & Easy resorption, good adhesion \\
\hline & & $50<x<200$ & & Long-term stability, but reduced adhesion \\
\hline Pore size $(\mu \mathrm{m})$ & & $>75$ & & Optimum cell in-growth \\
\hline HA content $(\%)$ & $>95$ & $>95$ & $>50$ & Chemical stability \\
\hline Non-apatitic CaP (\%) & & & $<5$ each & High resorption \\
\hline Crystallinity (\%) & $>62$ & $>90$ & $>45$ & Resorption resistance \\
\hline Trace elements (ppm) & $<50$ & & $<45$ & Biocompatibility, non-toxicity \\
\hline Adhesion strength (MPa) & & $>35$ & $>15$ & Implant integration, stability against delamination \\
\hline Tensile strength $(\mathrm{MPa})$ & $>51$ & & & Internal coating integrity, crack resistance \\
\hline Shear strength $(\mathrm{MPa})$ & $>22$ & & & In vivo adhesion \\
\hline $\mathrm{Ca} / \mathrm{P}$ ratio & & & $1.67-1.76$ & Phase purity, low solubility \\
\hline
\end{tabular}



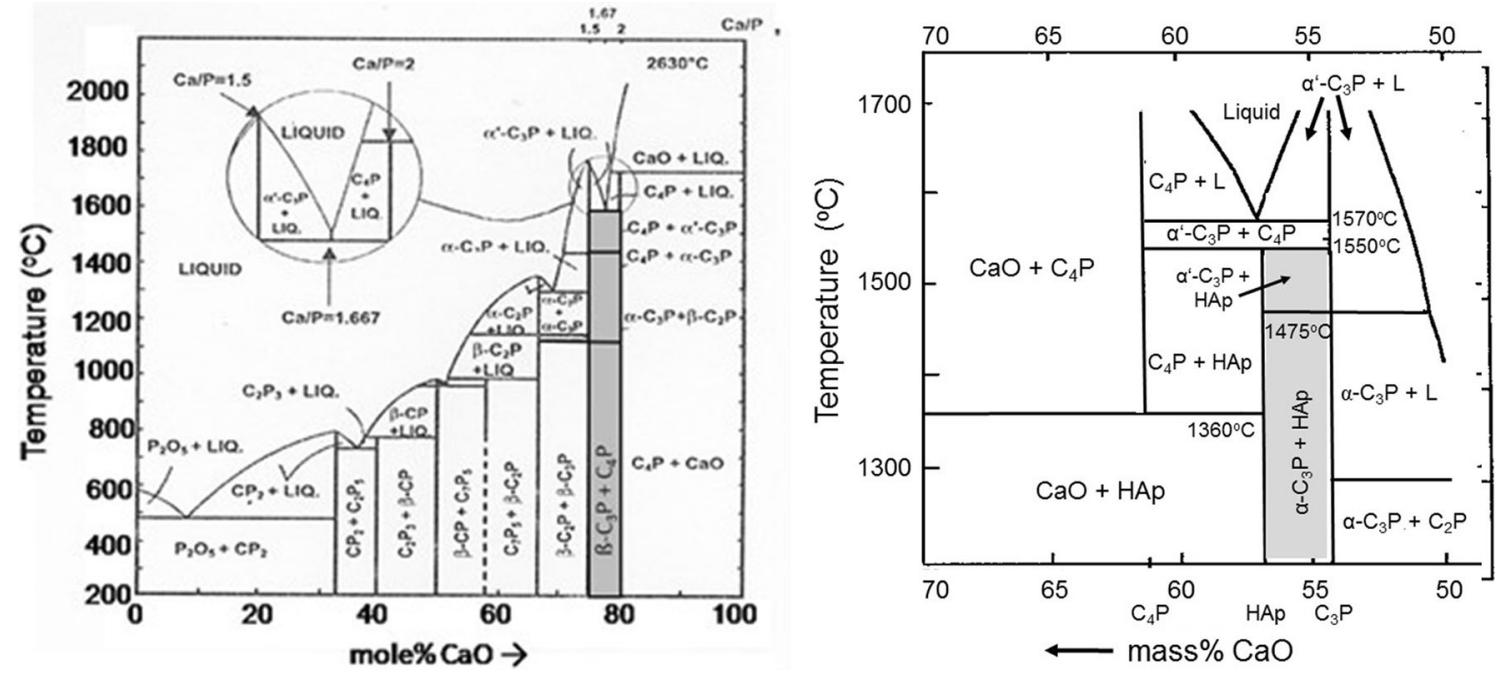

Fig. 4 Left: Binary phase diagram of $\mathrm{CaO}-\mathrm{P}_{2} \mathrm{O}_{5}$ in the absence of water (Ref 88). The inset shows the region of interest, i.e., the incongruent thermal decomposition of hydroxylapatite $(\mathrm{Ca} / \mathrm{P}=1.67)$ to $\alpha^{\prime}$-tricalcium phosphate $(\mathrm{Ca} / \mathrm{P}=1.5)$ and tetracalcium phosphate $(\mathrm{Ca} / \mathrm{P}=2)$. Right: Phase diagram of the quasi-binary system CaO- $\mathrm{P}_{2} \mathrm{O}_{5}-\left(\mathrm{H}_{2} \mathrm{O}\right)$ at a water partial pressure of $65.5 \mathrm{kPa}($ after Ref 89$)$. Note that incongruent melting of hydroxylapatite (HA) occurs beyond $1570{ }^{\circ} \mathrm{C}$, accompanied by formation of $\alpha^{\prime}-\mathrm{C}_{3} \mathrm{P}\left(\alpha^{\prime}-\mathrm{TCP}\right)$ and $\mathrm{C}_{4} \mathrm{P}$ (TTCP)

Eventually, matrix vesicles bud from the plasma membrane at sites of interaction with the extracellular matrix (ECM), and in this way provide calcium and phosphate ions, lipids, and proteins that act to nucleate apatite. This process appears to be controlled by the speciation of the phosphate carrier. Pyro $\left[\mathrm{P}_{2} \mathrm{O}_{7}\right]^{4-}$ and polyphosphate $\left[\mathrm{P}_{\mathrm{n}} \mathrm{O}_{3 \mathrm{n}+1}\right]^{(\mathrm{n}+2)-}$ ions were found to inhibit mineralization, whereas hydrogen phosphate $\left[\mathrm{HPO}_{4}\right]^{2-}$ ions appear to stimulate nucleation outside the matrix vesicles in the interstitial space (ECM) and directly on triple-helical collagen I strands.

Moreover, hydroxylapatite-based bioactive implant coatings promote normal differentiation in surrounding tissues by providing a fertile environment for enhanced cell adhesion (Ref 74) and biocompatibility, including reduction of bacterial adhesion in dental implantology (Ref 75). Cytoskeletal microfilaments such as actin, myosin, actinin, and tropomyosin that control cell shape and migration will be coupled through specialized cell membrane proteins (integrins) to extracellular adhesion molecules such as fibronectin, laminin, vitronectin, or thrombospondin (Ref 76). An interfacial layer of hydroxylapatite will adsorb these adhesion molecules in a favorable conformation and promote the formation of focal adhesion centers. Particular growth factors (cytokines) may also be adsorbed at specific hydroxylapatite surfaces, thus further promoting osseointegration. These growthsupporting cytokines include transforming growth factor- $\beta$, insulin-like growth factor-1, tumor necrosis factor- $\alpha$, or recombinant human bone morphogenetic proteins (rhBMPs) that all provide a degree of osteostimulation that support the transformation of undifferentiated mesenchymal precursor cells into osteoprogenitor cells pre- ceding endochondral ossification. This is at the very heart of the mechanism of osteoinduction.

In conclusion, Fig. 3a shows a schematic representation of osteoinduction induced by adsorption and incorporation of cell membrane proteins into the bone-like hydroxylapatite layer precipitated onto the dissolving calcium phosphate coating. The increased concentration of $\mathrm{Ca}^{2+}$ and $\mathrm{PO}_{4}{ }^{3-}$ ions appears to stimulate the release of chemokines from the cortical bone bed (Ref 77). Figure $3 \mathrm{~b}$ is a schematic rendering of the dynamic behavior of the interface between implant (left) and bone (right). Remodeling of the interface zone occurs at all dimensional levels from the molecular up to the cell and tissue levels, and at any time scale from the first few seconds after implantation up to several years (Ref 174). Immediately following the implantation, a space filled with biofluid exists adjacent to the hydroxylapatitecoated implant surface (left). With time, bone growthsupporting proteins will be adsorbed at the coating surface that will give rise to osteointegration by proliferation of stem cells and their differentiation toward bone cells, revascularisation, and eventual gap closing. The direction of closing is a two-way affair: new bone matter grows into the gap from cortical bone as well as from the implant surface.

\section{Critical Properties and Key Parameters of Plasma-Sprayed Hydroxylapatite Coatings}

Hydroxylapatite coatings deposited by plasma spray techniques will have properties differing in chemical and 

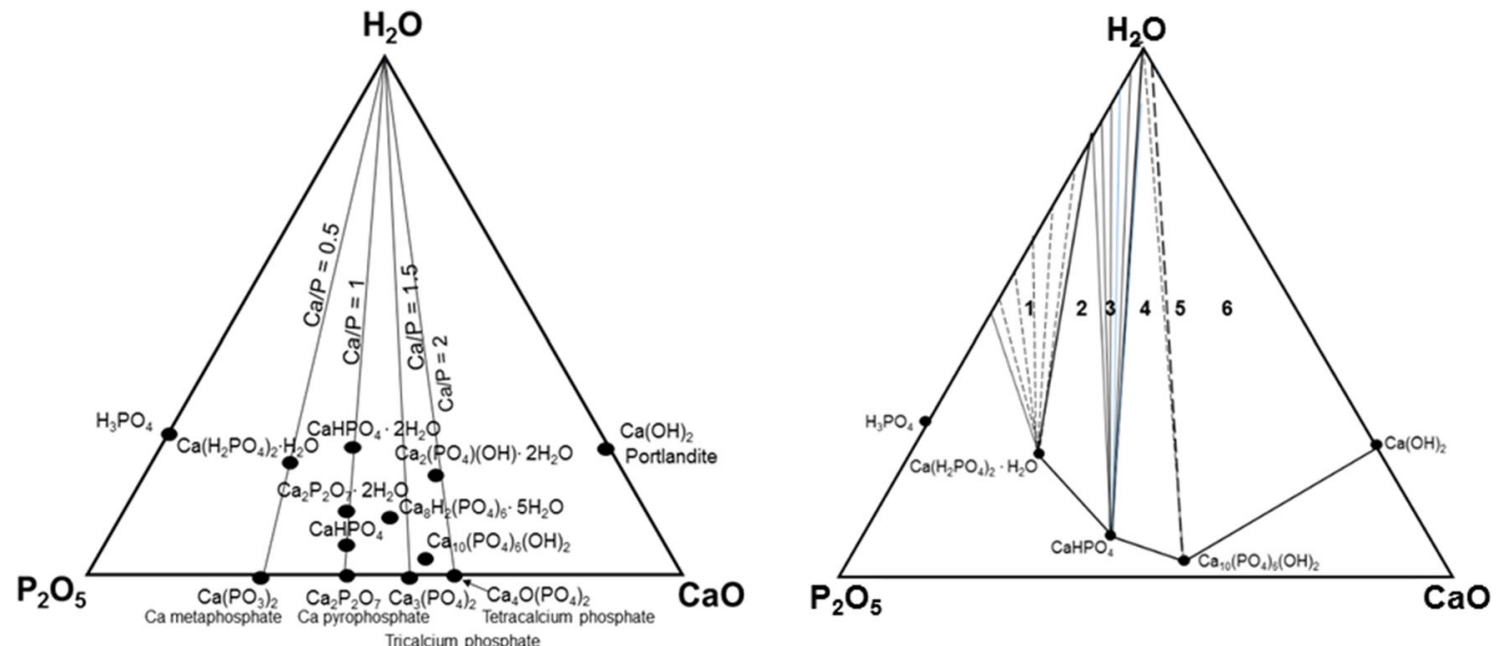

Fig. 5 Left: Theoretical composition of solid ternary phases in the pseudo-ternary system $\mathrm{CaO}-\mathrm{P}_{2} \mathrm{O}_{5}-\mathrm{H}_{2} \mathrm{O}$, showing the isopleths $0.5<\mathrm{Ca} / \mathrm{P}<2$. Right: Equilibrium phase diagram $\mathrm{CaO}-\mathrm{P}_{2} \mathrm{O}_{5}-\mathrm{H}_{2} \mathrm{O}$ under hydrothermal conditions $\left(300{ }^{\circ} \mathrm{C}, 2 \mathrm{kbar}\right.$ water pressure $)$. The fields of existence of individual phases are as follows: $1 \mathrm{Ca}\left(\mathrm{H}_{2} \mathrm{PO}_{4}\right)_{2} \cdot \mathrm{H}_{2} \mathrm{O}+$ fluid, $2 \mathrm{CaHPO}_{4}+\mathrm{Ca}\left(\mathrm{H}_{2} \mathrm{PO}_{4}\right)_{2} \cdot \mathrm{H}_{2} \mathrm{O}+$ fluid, $3 \mathrm{CaHPO}+\mathrm{fluid}$, $4 \mathrm{CaHPO}_{4}+\mathrm{Ca}_{10}\left(\mathrm{PO}_{4}\right)_{6}(\mathrm{OH})_{2}+$ fluid, $5 \mathrm{Ca}_{10}\left(\mathrm{PO}_{4}\right)_{6}(\mathrm{OH})_{2}+$ fluid, $6 \mathrm{Ca}_{10}\left(\mathrm{PO}_{4}\right)_{6}(\mathrm{OH})_{2}+\mathrm{Ca}(\mathrm{OH})_{2}+$ fluid (modified and redrawn after Ref 90)

Table 2 Thermal decomposition sequence of hydroxylapatite

Step 1: $\mathrm{Ca}_{10}\left(\mathrm{PO}_{4}\right)_{6}(\mathrm{OH})_{2}$ (hydroxylapatite) $\rightarrow \mathrm{Ca}_{10}\left(\mathrm{PO}_{4}\right)_{6}(\mathrm{OH})_{2-2 x} \mathrm{O}_{x} \square x+x \mathrm{H}_{2} \mathrm{O}$ (oxyhydroxylapatite)

Step 2: $\mathrm{Ca}_{10}\left(\mathrm{PO}_{4}\right)_{6}(\mathrm{OH})_{2-2 x} \mathrm{O}_{x} \square x$ (oxyhydroxylapatite) $\rightarrow \mathrm{Ca}_{10}\left(\mathrm{PO}_{4}\right)_{6} \mathrm{O}_{x} \square x+(1-x) \mathrm{H}_{2} \mathrm{O}$ (oxyapatite)

Step 3: $\mathrm{Ca}_{10}\left(\mathrm{PO}_{4}\right)_{6} \mathrm{O}_{x} \square x$ (oxyapatite) $\rightarrow 2 \mathrm{Ca}_{3}\left(\mathrm{PO}_{4}\right)_{2}$ (tricalcium phosphate) $+\mathrm{Ca} \mathrm{O}\left(\mathrm{PO}_{4}\right)_{2}$ (tetracalcium phosphate)

Step 4a: $\mathrm{Ca}_{3}\left(\mathrm{PO}_{4}\right)_{2} \rightarrow 3 \mathrm{CaO}+\mathrm{P}_{2} \mathrm{O}_{5}$

Step 4b: $\mathrm{Ca}_{4} O\left(\mathrm{PO}_{4}\right)_{2} \rightarrow 4 \mathrm{CaO}+\mathrm{P}_{2} \mathrm{O}_{5}$

phase composition, crystallinity, crystallite size, and defect density from the natural bone-like apatite they are supposed to mimic. On the one hand, these coatings must possess biomedical properties that influence positively their performance in vivo such as osteoconductivity or even osteoinductivity (see above). On the other hand, deleterious aspects inhibiting biocompatibility must be avoided. Required key coating properties include suitable coating thickness, stable phase composition and phase purity, absence of toxic elements, sufficiently high but limited crystallinity, adequate porosity and roughness, optimum surface microtopography, and high adhesive and cohesive strengths. An additional important requirement is successful control of deleterious residual coating stresses that may lead to premature chipping, spalling, or even complete delamination of coatings in vivo. During recent years, the quest to provide to the clinician coatings with such advantageous properties has triggered an avalanche of research contributions in the literature. Now virtually thousands of papers can be found in an ever-increasing number of relevant journals, using a plethora of deposition techniques, both thermal and non-thermal. Many of these attempts are discussed in a recent book on bioceramic coatings for medical implants (Ref 20).

As recently stressed by Groen et al. (Ref 14), the intrinsic complexity of the biological system 'human' is a crucial factor that is being often overlooked and oversimplified, respectively, when characterizing and evaluat- ing biological responses to materials introduced into the body with widely differing properties. Indeed, since in vitro tests designed to predict the in vivo performance of a given biomaterial frequently deliver ambivalent results, capturing the biological complexity of living tissue in a comprehensive in vitro model and establishing tractable property-function relationships are still not possible today.

Table 1 collects performance profiles and general property requirements of hydroxylapatite coatings for medical applications (Ref 78-80). The data provided by Callahan et al. (Ref 78) were subsequently used to formulate guidelines and recommendations issued by the U.S. Food and Drug Administration (Ref 49, 50). Additional information on material fundamentals and clinical performance of plasma-sprayed hydroxylapatite coatings can be found in Sun et al. (Ref 81). Quality standards including Quality Management Systems (QMS) requirements can be obtained from ISO 13485 (Ref 60), and standard specification for composition of HA from ASTM F1185-03 (Ref 59).

\subsection{Coating Thickness}

A thin HA layer $(<50 \mu \mathrm{m})$ yields better adhesion to the implant compared with thicker coatings (Ref 79; Table 1) due to the reduced residual coating stress of the former (Ref 82). During deposition, the substrate is usually 

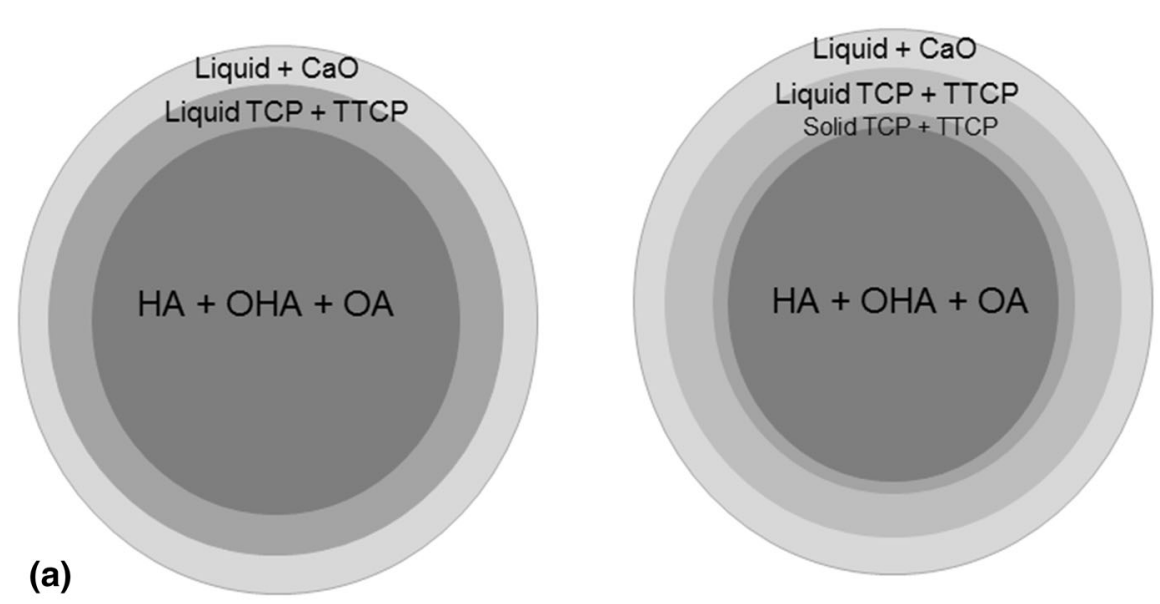

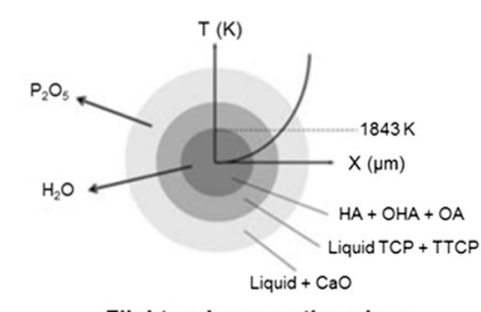

Flight and evaporation phase

(b)

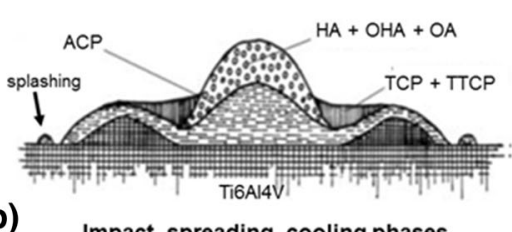

Impact, spreading, cooling phases

Fig. 6 (a) Schematic model of the thermal decomposition of a spherical hydroxylapatite particle subjected to high temperature in a plasma jet. Left: Mode of decomposition at a high water partial pressure of $65.5 \mathrm{kPa}$ (Ref 89, 91, 97; see Fig. 4, right). Right: Mode of decomposition at a very low water partial pressure of $1.3 \mathrm{kPa}$ (Ref 94; see Fig. 4, left). (b) Phase distributions during flight of a plasmaheated spherical hydroxylapatite particle (top), and after impact, splashing, spreading, and cooling (bottom) (Ref 98) (ㄷ With permission by John Wiley and Sons)

at some elevated temperature that on post-depositional cooling to ambient temperature leads to strong thermal mismatch, causing coating stress owing to the difference in the thermal expansion coefficients of the coating and the substrate. Depending on the sign of this difference, this 'thermal' stress can be either tensile or compressive.

However, residual stress will be quickly relaxed in the course of bone integration in vivo as also confirmed by in vitro tests (Ref 83). Although thick coatings $( \pm 150 \mu \mathrm{m}$, Fig. 2c) show significantly reduced adhesion strength, they may be required in some instances to ensure a more permanent bond to guarantee implant stability by a lasting biological effect (Ref 53, 84, 85). This is particularly evident when, during an endoprosthetic replacement operation involving an exchange of the implant, the bone matter has been previously damaged, often in concurrence with an undesirable geometric configuration of the implantsupporting cortical bone. In this special case, a thin, quickly resorbed calcium phosphate coating will not be sufficient to sustain the required large-scale and, thus, long-time bone regeneration (Ref 85). Rather, thicker coatings will be required. Clearly, there is a contradiction between the need for strong adhesion of the coating to the substrate, and the need for thicker coatings to provide a lasting biological effect that supports bone regeneration over long time. Here, careful design of plasma spray conditions and stringent quality management are called for to obtain an optimum trade-off solution.

\subsection{Phase Composition and Crystallinity}

Phase composition and degree of crystallinity of the coatings are of vital importance for their in-service performance, as both properties control the in vivo dissolution behavior (Ref 86,87 ). In the binary phase diagram $\mathrm{CaO}-\mathrm{P}_{2} \mathrm{O}_{5}$ shown in Fig. 4, many compositions are present of which only a few are of biological relevance in the context of osteoconductive coatings. These are hydroxylapatite $(\mathrm{Ca} / \mathrm{P}=1.67)$, tricalcium phosphate $(\mathrm{Ca} / \mathrm{P}=1.5)$, and tetracalcium phosphate $(\mathrm{Ca} / \mathrm{P}=2)$.

Furthermore, the pseudo-ternary system $\mathrm{CaO}-\mathrm{P}_{2} \mathrm{O}_{5^{-}}$ $\mathrm{H}_{2} \mathrm{O}$ (Fig. 5, left) contains, in addition to hydroxylapatite, calcium phosphate hydrate phases such as octacalcium phosphate $(\mathrm{Ca} / \mathrm{P}=1.33)$ and brushite $(\mathrm{Ca} / \mathrm{P}=1)$ that are of interest as precursor phases toward precipitation of stable hydroxylapatite from biofluid. However, stable equilibrium phases under hydrothermal conditions $\left(300^{\circ} \mathrm{C}, 2\right.$ kbar) are calcium dihydrogenphosphate monohydrate, $\mathrm{Ca}\left(\mathrm{H}_{2} \mathrm{PO}_{4}\right)_{2} \cdot \mathrm{H}_{2} \mathrm{O}$; monetite, $\mathrm{CaHPO}_{4}$; hydroxylapatite; and portlandite, $\mathrm{Ca}(\mathrm{OH})_{2}$ (Fig. 5, right; Ref 90).

5.2.1 Dehydroxylation and Thermal Decomposition of Hydroxylapatite. Hydroxylapatite powder particles subjected to the extremely high temperature of a plasma jet in excess of $15,000{ }^{\circ} \mathrm{C}$ undergo, even during their very short residence time (hundreds of microseconds to few milliseconds) in the hot zone of the jet, dehydroxylation and thermal decomposition by incongruent melting. This thermal decomposition sequence occurs in four consecutive steps (Table 2).

Based on this decomposition sequence, several models were developed (Ref 91-94) of the in-flight evolution of individual calcium phosphate phases. Figure 6a shows models of thermally induced phase transformation within a spherical hydroxylapatite particle, considering a parabolic temperature gradient according to Fourier's Law. During the very short residence time of the particle in the plasma jet, the innermost core is still at a temperature well below $1550{ }^{\circ} \mathrm{C}$, the result of the low thermal diffusivity of hydroxylapatite of about $4.5 \times 10^{-3} \mathrm{~cm}^{2} / \mathrm{s}$ at $1000^{\circ} \mathrm{C}(\operatorname{Ref}$ 95). Consequently, hydroxylapatite (HA) and oxyhydroxy/ oxyapatite (OHA/OA) are the only phases present (Table 2 , reactions 1 and 2 ).

At a high water partial pressure, the second shell heated to a temperature above the incongruent melting point 

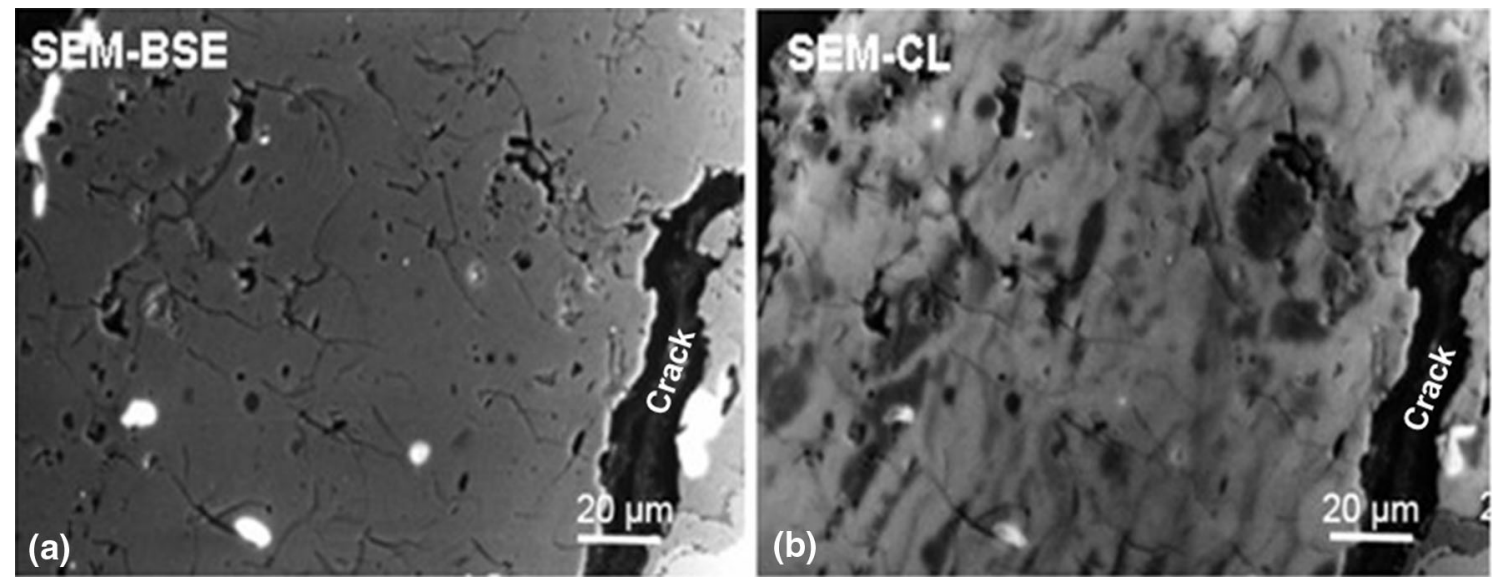

Fig. 7 (a) SEM image in back-scattered electron (BSE) mode of a plasma-sprayed hydroxylapatite coating, suggesting at first glance a homogeneous phase composition and showing intrinsic coating porosity (medium gray) as well as particle pull-out during sample polishing (dark gray). (b) SEM image of the same sample area in cathodoluminescence (CL) mode. Amorphous calcium phosphate (ACP) appears in the form of dark patches embedded in a mixture of hydroxylapatite and oxyhydroxylapatite. ACP has formed as a product of quenching of Ca-deficient melt (Ref 111)

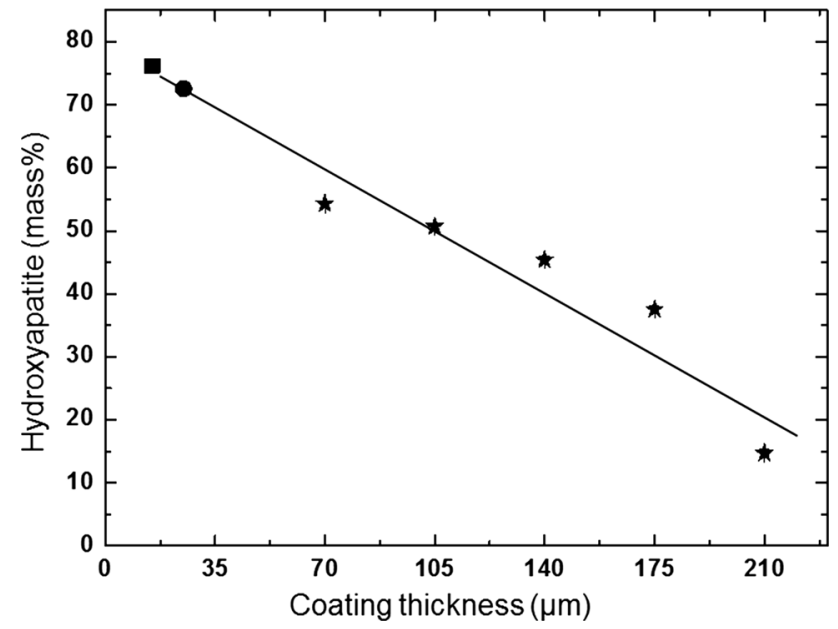

Fig. 8 Linear decrease of HA content with coating depth, determined with conventional $\mathrm{x}$-ray diffraction $(8 \mathrm{keV}$, square) and synchrotron radiation $\mathrm{x}$-ray diffraction $(11 \mathrm{keV}$, dot; $100 \mathrm{keV}$, stars) (Ref 112). The diffracted synchrotron radiation was recorded using a 345-mm-diameter 2D MAR image plate detector (marXperts GmbH, Norderstedt, Germany) (c) With permission by Elsevier)

of hydroxylapatite $\left(1570{ }^{\circ} \mathrm{C}\right)$ consists of a molten mixture of tri- and tetracalcium phosphates (Table 2, reaction 3). The outermost spherical shell of the particle comprises solid $\mathrm{CaO}+$ melt since evaporation of $\mathrm{P}_{2} \mathrm{O}_{5}$ or, more likely, loss of $\mathrm{P}$ generated by reduction of $\mathrm{P}_{2} \mathrm{O}_{5}$ in the $\mathrm{H}_{2}$ rich plasma plume (Ref 96) shifts the composition along the liquidus toward $\mathrm{CaO}$-richer phases (Table 2, reaction 4). The temperature increases to well beyond $1800{ }^{\circ} \mathrm{C}$, and the only unmelted composition is $\mathrm{CaO}$ (see Fig. 9, position 5).

Although the presence of OHA as products of partial dehydroxylation of hydroxylapatite was postulated and confirmed early (Ref 99, 100), the existence of OA was subject to controversy for many years until it has now been well established thanks to modern analytical tools such as synchrotron radiation $\mathrm{x}$-ray diffraction and solid-state nuclear magnetic resonance spectroscopy (Ref 101). Liao et al. (Ref 102) reported that small amounts of $\mathrm{OH}^{-}$ions are always required to stabilize the structure of OA and that even a loss as high as $75 \%$ of the chemically bound hydroxyl ions maintains the apatite channel structure. The limiting composition is then $\mathrm{Ca}_{10}\left(\mathrm{PO}_{4}\right)_{6}(\mathrm{OH})_{0.5} \mathrm{O}_{0.75} \square_{0.75}$, corresponding to a water loss of 1.34 mass\% (Ref 103 ). Hence, partially dehydroxylated hydroxylapatite (designated oxyhydroxylapatite, OHA) could be described either as a non-stoichiometric defect hydroxylapatite with distorted structure (Ref 104, 105) or a 50:50 solid solution of stoichiometric HA and oxyapatite (Ref 95).

Dyshlovenko et al. (Ref 94) presented the modified model shown on the right of Fig. 6a that includes the product of the solid-state dehydration transformation of HA into TCP and TTCP between 1360 and $1570{ }^{\circ} \mathrm{C}$ (Fig. 4, left). These phases have been experimentally (Ref 102) detected at very low water partial pressure (Fig. 6a, right). Hence, the second shell heated to a temperature of $1360<T<1570{ }^{\circ} \mathrm{C}$, just below the incongruent melting point of HA, undergoes solid-state decomposition to a mixture of $\alpha^{\prime}$-TCP and TTCP. The third shell, heated to a temperature above $1570{ }^{\circ} \mathrm{C}$, consists of melt with a $\mathrm{Ca} / \mathrm{P}$ ratio of 1.67 (Table 2, reaction 3; Ref 97). The outermost fourth shell is composed of some solid $\mathrm{CaO}$ and melt phases of various compositions, the $\mathrm{Ca} / \mathrm{P}$ ratio of which shifts by continuous loss of $\mathrm{P}_{2} \mathrm{O}_{5}$ along the liquidus of the binary phase diagram $\mathrm{CaO}-\mathrm{P}_{2} \mathrm{O}_{5}$ toward $\mathrm{CaO}$-richer phases, i.e., TTCP (Table 2, reaction 4).

On impact with the target surface, the molten phase is rapidly quenched and will solidify quickly to produce ACP with various $\mathrm{Ca} / \mathrm{P}$ ratios (Ref 97, 106, 107). The force of impact of droplets accelerated to supersonic velocity triggers a series of events that profoundly affect the composition and the morphology of the resulting coating. 


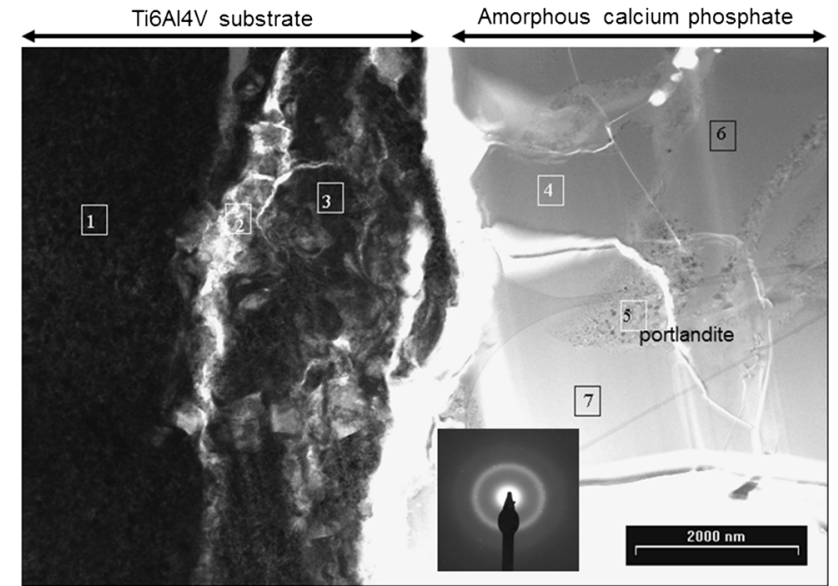

Fig. 9 Scanning transmission electron microscopy (STEM) image of the substrate-coating interface of a FIB (focused ion beam)-generated sample of plasma-sprayed hydroxylapatite. The inset shows the electron diffraction pattern of ACP, characterized by a diffuse single ring with radius $d=0.809 \mathrm{~nm}$ that suggests short-range order (SRO) configuration corresponding to $\{010\}$ of hydroxylapatite

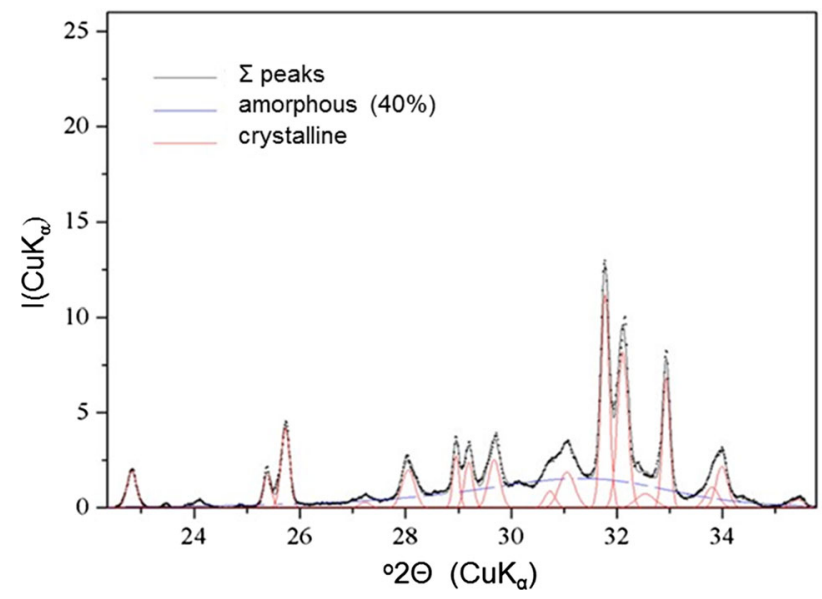

Fig. 10 Non-linear least-square fitting (Ref 114) to determine the content of ACP of a HA coating plasma-sprayed with plasma power of $24 \mathrm{~kW}$

The neatly ordered succession of spherical shells shown in Fig. 6a will be destroyed by the impact and will form a jumble of intermingled phases, i.e., patches of ACP in close vicinity to mixtures of hydroxylapatite and oxyhydroxylapatite (Fig. 6b, 7b). In addition, the impact of particles accelerated to supersonic velocity may create a shock wave moving into the substrate, the reverberation of which causes local heating by isentropic expansion that is able to re-melt some of the already solidified coating components (Ref 108, 109; see also Ref 110).

In addition to compositional inhomogeneity caused by lateral splat spreading, the phase composition of the coating varies considerably with depth. Indeed, depth-resolved diffraction studies of conventional x-rays and synchrotron radiation showed that the hydroxylapatite content decreases linearly with coating depth from about 75 mass \% at the free coating surface down to 15 mass \% at the surface-coating interface (Fig. 8). At the coating surface, the remainder of crystalline phases were found to be 15 mass $\%$ TTCP, 4 mass $\% \beta$-TCP, and 1.5 mass $\% \mathrm{CaO}$. These values decrease to 3 mass $\%$ TTCP, and 0.5 mass $\%$ each of $\beta$-TCP and $\mathrm{CaO}$ at the substrate-coating interface. The balance is thought to constitute ACP, reaching about $80 \%$ at the substrate-coating interface owing to rapid quenching of the arriving molten droplets (Ref 112). This ACP layer that formed immediately adjacent to the metallic substrate is shown in the scanning transmission electron microscopy (STEM) image of Fig. 9.

Figure 9 shows a FIB (focused ion beam)-generated cross section of a plasma-sprayed calcium phosphate coating (right, positions 4-7) on a Ti6Al4V substrate (left, positions 1 and 3). The alumina grit-blasted Ti6Al4V reveals heavy surface damage with fold-over (position 3), thereby enwrapping residual alumina grit particles (position 2). The ACP layer is approximately $5 \mu \mathrm{m}$ thick with an average $\mathrm{Ca} / \mathrm{P}$ ratio of 1.38 (position $4: \mathrm{Ca} / \mathrm{P}=1.38$; position $6: \mathrm{Ca} / \mathrm{P}=1.43$; position $7: \mathrm{Ca} / \mathrm{P}=1.32$ ). Beyond this amorphous layer there is a fully crystalline region of close to stoichiometric $\mathrm{HA}$ (not shown) with $\mathrm{Ca} / \mathrm{P}=\sim 1.67$. Position 5 indicates portlandite, $\mathrm{Ca}(\mathrm{OH})_{2}$, the product of the reaction with atmospheric humidity of $\mathrm{CaO}$ formed according to reactions $4 \mathrm{a}$ and $\mathrm{b}$ (Table 2). The transformation of ACP to HA preferentially occurs along cracks in the coating suggesting that the crack energy released may be a driving force for the solid-state transformation reaction. While the $\mathrm{Ca} / \mathrm{P}$ ratio of the $\mathrm{ACP}$ is initially fixed by the dehydration reactions 1 and 2 (Table 2) at $\mathrm{Ca} /$ $\mathrm{P}=1.67$, it can be shifted to values $<1.67$ depending on how much TCP is being dissolved in the melt. In this case, during cooling ACP transforms to TCP and TTCP without changing the global $\mathrm{Ca} / \mathrm{P}$ ratio of the $\mathrm{ACP}$. The relative amounts of TCP, TTCP, and $\mathrm{CaO}$ formed depend on the decomposition rate of HA (Ref 97). High decomposition rate achieved at high plasma enthalpies leads to large amounts of TCP + TTCP + ACP and subsequent decomposition of TTCP into $\mathrm{CaO}+\mathrm{P}_{2} \mathrm{O}_{5}$ (Table 2, reaction $4 b$ ). The TCP will completely dissolve in the melt, the $\mathrm{Ca} / \mathrm{P}$ ratio of which will then approach 1.5 . On cooling, crystallization of only TCP occurs. Conversely, a low decomposition rate at lower plasma enthalpy leads to a substantially reduced amount of TCP + TTCP + ACP. The $\mathrm{Ca} / \mathrm{P}$ ratio of the melt approaches 1.67 and on cooling HA with some TTCP and TCP will crystallize. This has been experimentally confirmed by Gross et al. (Ref 113) who showed that $\mathrm{OH}$-bearing $\mathrm{ACP}$ with $\mathrm{Ca} / \mathrm{P}=1.67$ crystallizes on heating to a temperature as low as $510{ }^{\circ} \mathrm{C}$ to form stoichiometric HA. However, usually no $\mathrm{OH}^{-}$can be detected in ACP, and crystallization may be associated with $\mathrm{OH}^{-}$formation according to $\mathrm{O}^{2-}+\mathrm{H}_{2} \mathrm{O} \rightarrow 2 \mathrm{OH}^{-}$ (Ref 96).

The assumed sequence of phase formation is also corroborated by the results shown in Fig. 13a.

5.2.2 Coating Crystallinity. Table 1 indicates that coating crystallinity of at least $45 \%$ has been specified as requirement for suitably bioactive HA coatings (ISO 


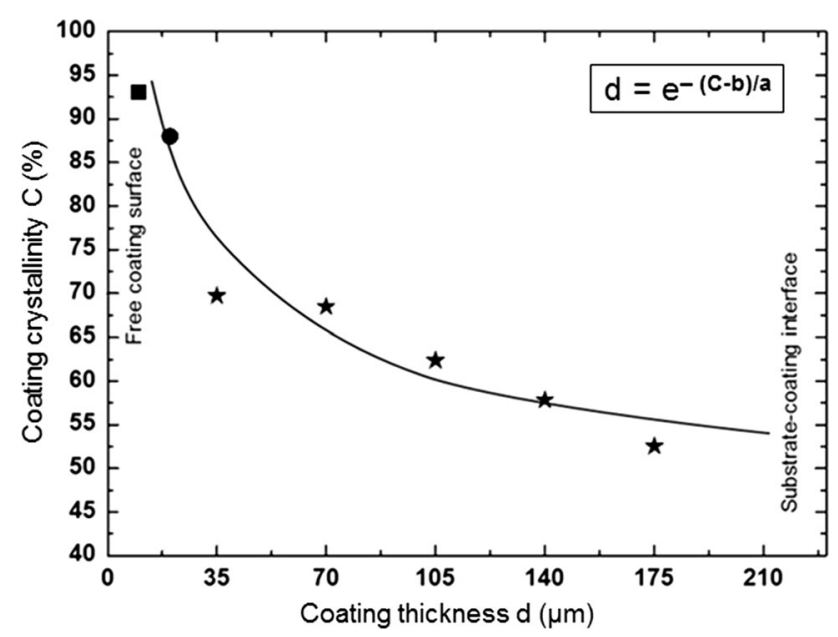

Fig. 11 Exponential decrease of crystallinity of a plasmasprayed HA coating with coating depth, determined with conventional $\mathrm{x}$-ray diffraction $(8 \mathrm{keV}$, square) and synchrotron radiation $\mathrm{x}$-ray diffraction $(11 \mathrm{keV}$, dot; $100 \mathrm{keV}$, stars) (Ref 112). The coefficients of the exponential decay equation are $a=-14.3, b=128.3$ (ㄷ With permission by Elsevier)

13779-2 2008). Analytical methods to determine coating crystallinity include conventional (Ref 114) and synchrotron radiation x-ray diffraction (Ref 112), Raman microspectroscopy (Ref 115,116$)$, as well as spatially resolved cathodoluminescence microscopy (Ref 111, 117).

Keller \& Dollase's method (Ref 114) consists of nonlinear last-squares fitting of the area of crystalline peaks and the broad amorphous 'hump' between $25^{\circ}$ and $35^{\circ} 2 \theta$ with a centroid value at $31.5^{\circ} 2 \theta$. The amount of ACP in a mixture of unknown proportions is obtained from the measured 'hump' fraction by a linear expression that requires only a single calibration constant. Figure 10 shows a synchrotron radiation $\mathrm{x}$-ray diffraction pattern of a plasma-sprayed HA coating with about 40\% ACP (Ref 98). The coating was obtained from hydroxylapatite powder with average grain size of $120 \mu \mathrm{m}$. Plasma spray parameters were as follows: plasma power at $24 \mathrm{~kW}$, total plasma gas flow rate at $50 \mathrm{slpm}$, powder feed rate at $18 \mathrm{~g} / \mathrm{min}$, spray distance at $100 \mathrm{~mm}$, and translation speed at $0.5 \mathrm{~m} / \mathrm{s}$. The only crystalline phases discernible were oxyapatite (Powder Diffraction File 89-649) and $\beta$-tricalcium phosphate (Powder Diffraction File 9-016978).

Depth-resolved analysis of the crystallinity distribution of plasma-sprayed HA coatings (Fig. 11) shows an exponential decrease in crystallinity from $93 \%$ in the nearsurface region to $53 \%$ near the coating-substrate interface. The decrease follows the equation $d=e^{-(C-b) / a}$, where $a=-14.3, b=128.3$, and goodness of fit $r^{2}=0.97$, neglecting the apparent outlier at $d=35 \mu \mathrm{m}$ (Ref 112). Since each subsequently deposited layer reheats the previously deposited, cooling layer, the temperature difference, as well as the cooling rate decrease exponentially with increasing coating thickness, controlled by Fourier's law. On the one hand, increasing temperature means less quenching of the subsequently arriving droplet, resulting in reduction in amorphicity and thermal decomposition products as the coating thickens. On the other hand, provided the temperature is high enough, the incoming droplet will anneal the previously quenched phases. Under such condition, the thermal decomposition products may reconstruct to form HA.

In addition to conventional diffraction techniques, spatially resolved cathodoluminescence (CL) microscopy may be used as a sensitive analytical tool to study the real structure of HA coatings deposited on implant surfaces. In particular, this technique provides a unique method to distinguish between crystalline and amorphous phases within such coatings (Ref 111, 117). Figure $7 \mathrm{~b}$ shows patches of ACP scattered throughout the crystalline calcium phosphate phases. This patchy distribution of ACP is the result of the quenching of molten or semi-molten droplets of hydroxylapatite during impact at the substrate surface whereby the ACP will be scattered among the crystalline constituents (Fig. 6b). Microanalyses of coatings conducted by Gross and Phillips (Ref 117) with scanning cathodoluminescence microscopy confirmed that the darker regions in polished cross sections represent the amorphous phase as shown in Fig. 7b. The more intense cathodoluminescence emission from the amorphous phase during electron-beam irradiation compared with the lighter appearing crystalline phase can thus be used to distinguish structurally ordered (crystalline) and disordered (amorphous) areas within the same sample. By selecting the peak of the intrinsic electron emission at $450 \mathrm{~nm}$, it is possible to scan the surface with the electron beam, producing a map of ACP distribution in polished sections. In addition, such maps have been obtained by micro-Raman spectroscopy (Ref 115). Whereas cathodoluminescence microscopy, based on the different light emission from the amorphous phase and hydroxylapatite, is a useful tool for identifying and mapping the ACP constituent in plasma-sprayed coatings, it can also be used to differentiate among different degrees of carbonation in carbonated hydroxylapatites (CHA, Ref 118).

5.2.3 Solubility and Phase Transformation of Calcium Phosphate Phases. Not only the calcium phosphate phases shown in the phase diagrams of Fig. 4 and 5 have different chemical compositions as expressed by their $\mathrm{Ca} /$ $\mathrm{P}$ ratios, but they have also widely diverging solubility as shown in Fig. 12.

Well-crystallized HA is very stable at $\mathrm{pH}$ values above 4.5, showing essentially bioinert behavior (Ref 119) and an inhibiting effect on cell proliferation as confirmed by decreased levels of activity of the enzyme alkaline phosphatase (ALP; Ref 120) and the reduced secretion of the peptide hormone osteocalcin (Ref 121). As these proteins signal the degree of de novo bone formation, they are sensitive tools to determine the efficacy of osteoconductive activity of a biomaterial.

In contrast to this, ACP, thermal decomposition products such as tricalcium phosphate (TCP), tetracalcium phosphate (TTCP), and calcium oxide $(\mathrm{CaO})$ as well as the dehydroxylation products oxyhydroxylapatite (OHA) and/or oxyapatite (OA) show enhanced solubility in human extracellular fluid (hECF) and simulated body fluid (SBF) that follow the order (Ref 86) 


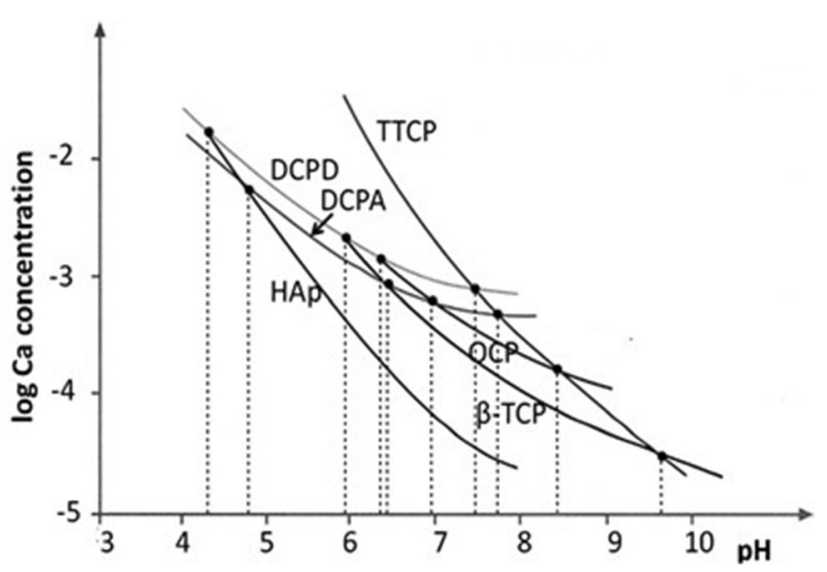

Fig. 12 Solubility isotherms of calcium phosphate phases of biological relevance as functions of the solution $\mathrm{pH}$. HAp, hydroxylapatite; DCPD, brushite; DCPA, monetite; $\beta$-TCP, $\beta$ tricalcium phosphate; OCP, octacalcium phosphate and TTCP, tetracalcium phosphate (redrawn after Ref 123)

$\mathrm{CaO}>>$ TCP $>$ ACP $>$ TTCP $>$ OHA $/ \mathrm{OA}>>$ HA.

(Eq 5.1)

Indeed, pure and well-crystallized hydroxylapatite is remarkably stable in the presence of aqueous solutions, showing a solubility product $\mathrm{K}_{\mathrm{ip}}=\left[\mathrm{Ca}^{2+}\right]^{5}\left[\mathrm{PO}_{4}^{3-}\right]^{3}\left[\mathrm{OH}^{-}\right]=$ $2.27 \times 10^{-58}(\operatorname{Ref} 122)$.

On the one hand, moderately enhanced levels of $\mathrm{Ca}^{2+}$ and $\mathrm{HPO}_{4}{ }^{2-}$ ions in the biofluid-occupied space at the interface implant-tissue are desired to assist in bone remodeling (Ref 124). On the other hand, excessive amounts of these ions released from the readily dissolving decomposition products of HA drive up the local $\mathrm{pH}$ values with concurrent cytotoxic effects on living bone cells (Ref 125, 126). Consequently, short-term release of high concentrations of ions from dissolving calcium phosphate phases must be kept at bay by optimizing the amount of well-crystallized HA in the as-sprayed coating. This can be achieved by several measures that include optimizing the set of plasma spray parameters that significantly influence the plasma enthalpy and in turn control the thermal history of HA (see, for example, Ref 93). In addition, the presence of a bioinert bond coat appears to improve the adhesion between HA coating and metal substrate (Ref 46,127$)$ and acts as a thermal barrier that may aid in enhanced crystallization of HA at the expense of ACP.

The formation of ACP by rapid quenching of the molten calcium phosphate droplets arriving at the cool substrate surface has several important implications. In addition to the patchy distribution of ACP in the bulk coating (see Fig. 7b), a thin layer of ACP formed adjacent to the interface substrate-coating (Fig. 9) provides a path of least energy for crack propagation thus forcing coating delamination when subjected to shear stresses during in vivo service (Ref 128). Second, owing to its easy solubility in contact with body fluid channeled by the throughcrack network down to the interface, ACP will be preferentially dissolved (Ref 86). Consequently, adhesion strength will be further reduced. Third, contact of ACP with body fluid will establish a series of dissolution-precipitation reactions that transform ACP into more Ca-rich compositions including Ca-deficient bone-like hydroxylapatite (Ref 111; see Fig. 13).

This reaction sequence leading from ACP to HA has been experimentally followed by immersion of plasmasprayed hydroxylapatite coatings into simulated body fluid mimicking the composition of human extracellular fluid (hECF). Incubation of calcium phosphate coatings in simulated body fluid is a generally applied fingerprint technique to determine the potential biocompatibility and osteoconductivity of coating. ACP transforms on contact with simulated body fluid to crystalline phases, presumably via progressive hydrolysis of $\mathrm{PO}_{4}{ }^{3-}$ groups. This transformation occurs predominantly along cracks and fissures in the coatings. Scanning transmission microscopy (STEM, Fig. 13a) reveals how the transformation front sweeping through the ACP phase leaves in its wake a body of porous crystalline hydroxylapatite as shown by its electron diffraction pattern (top right inset of Fig. 13a). At the leading edge of the transformation front, crystalline areas occur that can be identified by selected area electron diffraction (SAED) as $\beta$-TCP and TTCP. Presumably, these phases were formed already during coating deposition (Table 2, reaction 3). A zone of nano-crystalline material can be observed, the electron diffraction pattern of which reveals two diffuse rings with $d=0.282 \mathrm{~nm}$ and $d=0.251 \mathrm{~nm}$, corresponding to (211) and (301) planes, respectively. The electron diffraction pattern of the still pristine ACP ahead of the transformation front is characterized by a diffuse single ring with $d \sim 0.809 \mathrm{~nm}$ that suggests short-range order (SRO) configuration corresponding to $\{100\}$ of hydroxylapatite, a lattice plane with minimum specific free surface energy (Ref 129).

The high-resolution electron diffraction image of HA in the porous zone of Fig. 13a shows interplanar spacing at $0.344 \mathrm{~nm}$ (002), $0.306 \mathrm{~nm}$ (210), and $0.277 \mathrm{~nm}$ (Ref 112) (Fig. 13a, top right inset). In addition, weak diffraction rings appear presumably related to $\beta$-TCP (Fig. 13a, inset top left) as well as reflection spots of the $\langle 110\rangle$ zone of TTCP (Fig. 13a, inset left center). Larger single crystals of HA reveal in HRTEM micrographs (Fig. 13b) diffraction fringes spaced $0.39 \mathrm{~nm}$ apart, corresponding to $\{111\}$ of HA at $d=0.389 \mathrm{~nm}$.

Despite these results, it is not entirely clear how in detail the in vivo transformation occurs of $\mathrm{ACP}$ with a $\mathrm{Ca} /$ $\mathrm{P}$ ratio $<1.5$ to $\mathrm{HA}$ with a $\mathrm{Ca} / \mathrm{P}$ ratio of 1.67 . In a recent contribution, Luo et al. (Ref 73) used x-ray absorption near-edge spectroscopy (XANES) to confirm the transformation sequence ACP $\rightarrow \beta$-TCP $\rightarrow$ OCP $\rightarrow$ HA on phosphorylated bacterial cellulose (BC) nanofibers, thus providing new insight into the basic mechanism of biomineralization. The well-known transformation of OCP to HA was shown to be crystallographically controlled (Ref 131) since hydroxylapatite and octacalcium phosphate can form an epitaxial interface. The authors based this new OCP-HA interface model on an earlier configuration model proposed by Brown (Ref 132), using minimum interface free-energy optimization. In this way, 


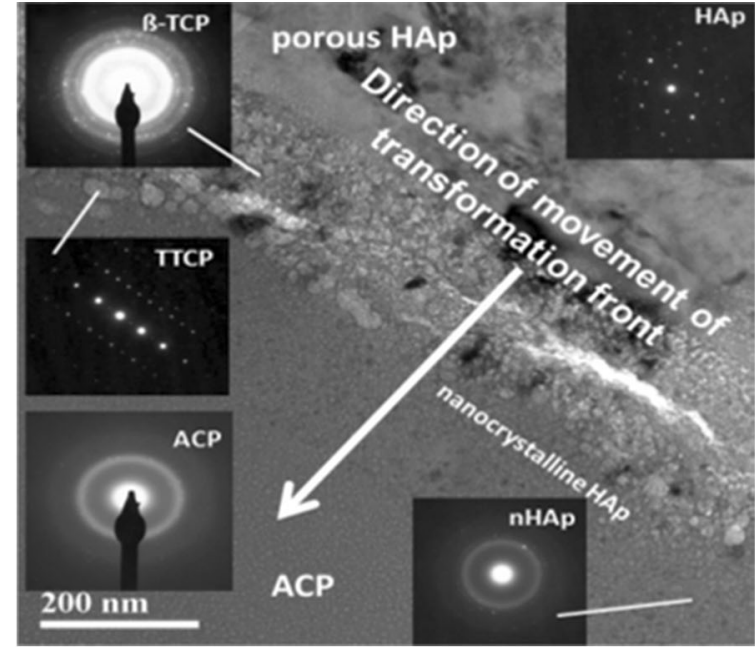

(a)

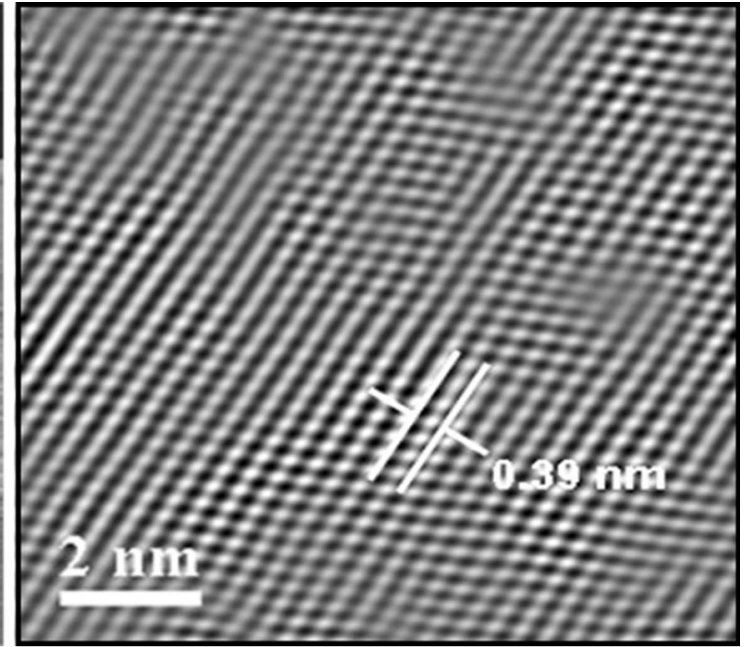

(b)

Fig. 13 (a) Scanning transmission electron microscope (STEM) image of transformation of ACP to crystalline phases on contact with simulated body fluid (H-SBF, Ref 130) for 1 week. At the trailing edge of the transformation front, well-crystallized HA forms, whereas at the leading edge nano-crystalline HA (n-HA) prevails (Ref 98). (c) With permission by John Wiley and Sons). (b) High-resolution transmission electron microscopy (HRTEM) diffraction fringes showing spacing of $d=0.389 \mathrm{~nm}$ that corresponds to $\{111\}$ of hydroxylapatite (Ref 98, 107) (C With permission by Elsevier)

a structure is formed that consists of half a unit cell of HA and one unit cell of OCP, whereby [00.1] of HA is parallel to [001] of OCP, and [12..0] of HA is parallel to [010] of OCP. It was shown by self-consistent field methods that the atoms in this model possess environments akin to those in the HA and OCP unit cells and that, because of the mismatch between HA and OCP unit cell parameters, this interface displays misfit dislocation-like features.

Fourier transform infrared spectroscopy-diffuse reflectance infrared reflection (FTIR-DRIFT) allows deconvoluting ACP spectra with the aim to provide deeper insight into the mechanism of transition of ACP to nano-crystalline HA (n-HA) in bone (Ref 133).

\subsection{Porosity and Surface Roughness}

5.3.1 Porosity. The porosity of plasma-sprayed hydroxylapatite coatings ranges between 3 and $20 \%$. Whereas high porosity is advantageous to enhance ingrowth of bone cells into the bioceramic coatings, tribological parameters such as friction and wear resistance, as well as corrosion resistance decrease dramatically with increasing porosity. Thus, porosity levels have to be tightly controlled to optimize coating performance.

Common causes of porosity of plasma-sprayed ceramic coatings include (Ref 134)

- formation of large, spherical pores around particles that have already solidified prior to impact or were never completely molten due to their large size,

- shadow effect when a later arriving particle splashes over previously arrived ones. This may leave a gap within the lamellar layer,

- narrow planar inter-lamellar pores and/or gas inclusions between the lamellae,
- 'exploded' particles due to rapid heating, excessive particle velocities and thus occurrence of disruptive shock waves (Ref 108),

- flat planar, crack-like pores formed during cooling as a result of stress relaxation originating from restricted thermal shrinkage,

- gas-filled voids caused by dissolution of gas in molten material,

- micropores originating from condensation of partially evaporated particles,

- formation of micro-cracks and voids by solidification, quenching, external loading, etc.

Porosity and surface roughness of hydroxylapatitebased coatings play decisive roles in the quest for enhancing the biomedical performance of endoprosthetic implants. While optimum coating porosity and roughness (Ref 79; Table 1) are mandatory requirements for ingrowth of bone cells, accumulation of macropores at the substrate/coating interface leads to an intolerable weakening of the coating adhesion as well as cohesion strengths. The denser the microstructure of the bioceramic coating, the lower is the risk of bonding degradation by cracking, spalling and delamination during in vivo contact with aggressive body fluids (Ref 135). Since the integrity and continuity of the substrate/coating interface is of paramount importance for implants, the two conflicting requirements of the need of porosity for easy bone cell ingrowth and the need of high coating density for superior adhesion have to be carefully considered, controlled, and adjusted (Ref 93). This is particularly important considering the risk of release of coating particles in vivo that will be distributed by the lymphatic system throughout the human body and is known to lead to inflammatory re- 


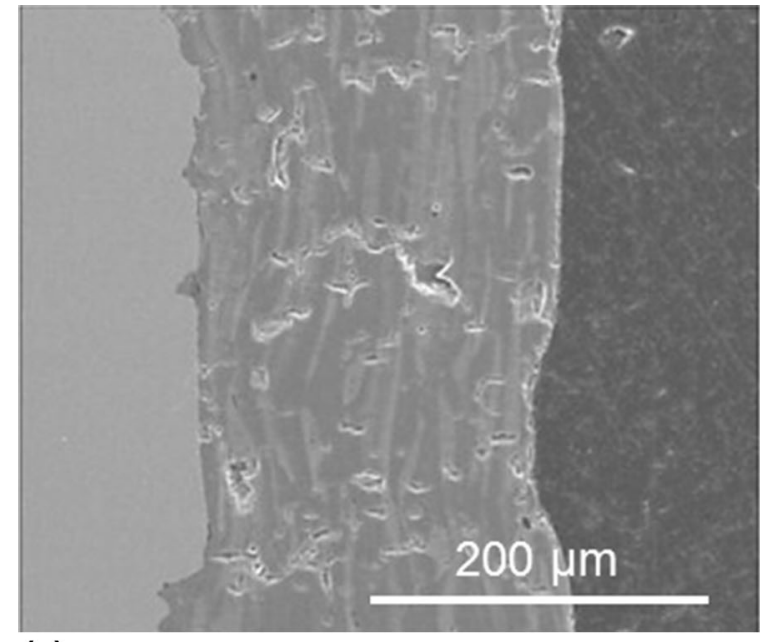

(a)

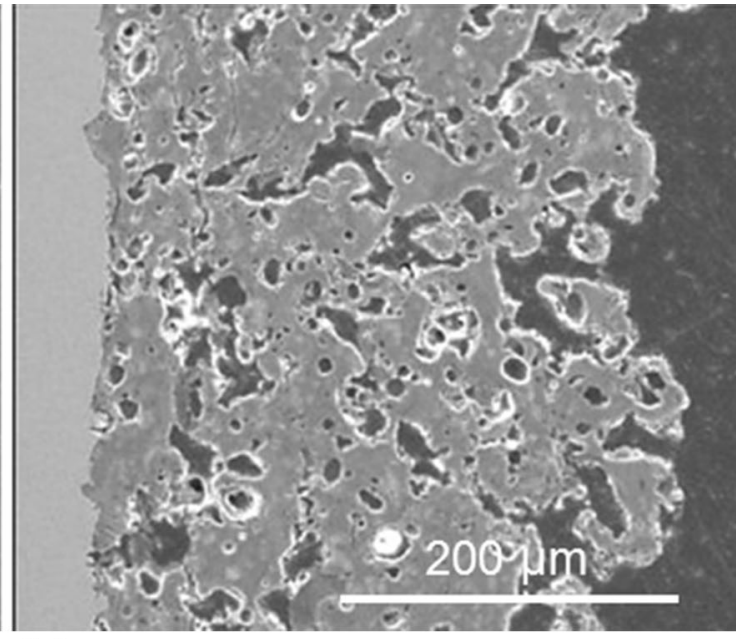

(b)

Fig. 14 Cross-sectional images of hydroxylapatite coatings deposited by (a) conventional atmospheric plasma spraying (APS) and (b) suspension plasma spraying (SPS) (Ref 34) (๔) With permission by Elsevier)

sponses with formation of undesirable giant cells and phagocytes (Ref 136). Hence, balancing the two conflicting porosity requirements is a considerable challenge apparent during designing and controlling appropriate intrinsic plasma spraying parameters.

As shown in Table 1, the size of pores should be at least $75 \mu \mathrm{m}$, preferably more (Ref 64, 137), to allow bone cells to grow easily and unimpeded into the coating fabric and thus to anchor the implant solidly to the surrounding cortical bone bed. This is a rather difficult task, as APS of hydroxylapatite usually leads to rather dense coatings with low porosity and small pores sizes (Fig. 14a). To remedy this disadvantage, Bouyer et al. (Ref 33) working at the Université de Sherbrooke, Québec, Canada invented induction plasma spraying of hydroxylapatite particles suspended in an aqueous solution instead of solid powder. The SPS route eliminates many potentially contaminating steps in coating preparation and allows for deposition of coatings with high deposition rates in excess of $150 \mu \mathrm{m} /$ min (Ref 138). In addition, decomposition of HA could be either avoided or at least minimized by the presence of water (Ref 35$)$ and by using appropriate plasma gases, i.e., a plasma-sheath gas mixture with moderate enthalpy and high oxidizing potential such as oxygen. The resulting coatings show acceptable levels of porosity around 30 vol. \% and pores sizes in excess of $20 \mu \mathrm{m}$ (Ref 34). Despite the presence of water, the high heating level required by SPS is sufficient to remove the hydroxide ions from the hydroxylapatite feedstock, leading to dehydroxylated and hence, highly reactive coatings rich in oxyhydroxy/oxyapatite. These SPS coatings are much more porous than APS coatings as shown in Fig. 14b. Although increased porosity causes a decrease in hardness and elastic modulus of the bulk coating, it will be advantageous for in-growth of bone cells and consequently may impart enhanced biocompatibility if sufficient coating adhesion to the implant surface can be engineered and maintained.
5.3.2 Surface Micro- and Nanotopography. Plasmasprayed coatings exhibit very different surface structures compared with homogeneous bulk materials. Whereas apparently smooth homogeneous bulk materials often show a surface characterized by wavy undulations and scratches, plasma-sprayed surfaces display an inhomogeneous profile given by the original splat structure, inherent coating porosity, as well as cracked, pulled-out, and chipped-off areas. To describe such surfaces according to their functional behavior in service, it is useful to separate the undulation, i.e., the waviness of the surface (macroroughness) from the roughness per se (micro-roughness) that is responsible for the tribological and biological behavior of the coating. In the case of bioceramic coatings, the degree of cell attachment and proliferation significantly depends on the type and numerical value of their surface roughness.

Adequate surface nanotopography is an important prerequisite for optimum cell adhesion and proliferation. To define the general nature of micro- and nano-roughened surfaces, the concept of fractals has been invoked (for example Ref 139, 140). Using a fractal approach, Gentile et al. (Ref 141) conducted experiments to study cell proliferation on electrochemically etched silicon proxy surfaces with varying roughness but comparable surface energies. The surface profiles were found to be self-affine fractals, the average roughness $R_{\mathrm{a}}$ of which increased with etching time from $\sim 2 \mathrm{~nm}$ to $100 \mathrm{~nm}$, with fractal dimension ranging from $D=2$ (a nominal flat surface) to $D=2.6$. Moderately rough surfaces with $R_{\mathrm{a}}$ between 10 and $45 \mathrm{~nm}$ yield a close to Brownian surface topography with $D \sim 2.5$. The authors interpreted the observed cell behavior with the theory of adhesion to randomly rough solids. They further concluded that a moderately rough surface with large fractal dimension is conducive to cell proliferation. In a more applied context, Gittens et al. (Ref 142) critically reviewed and interpreted 

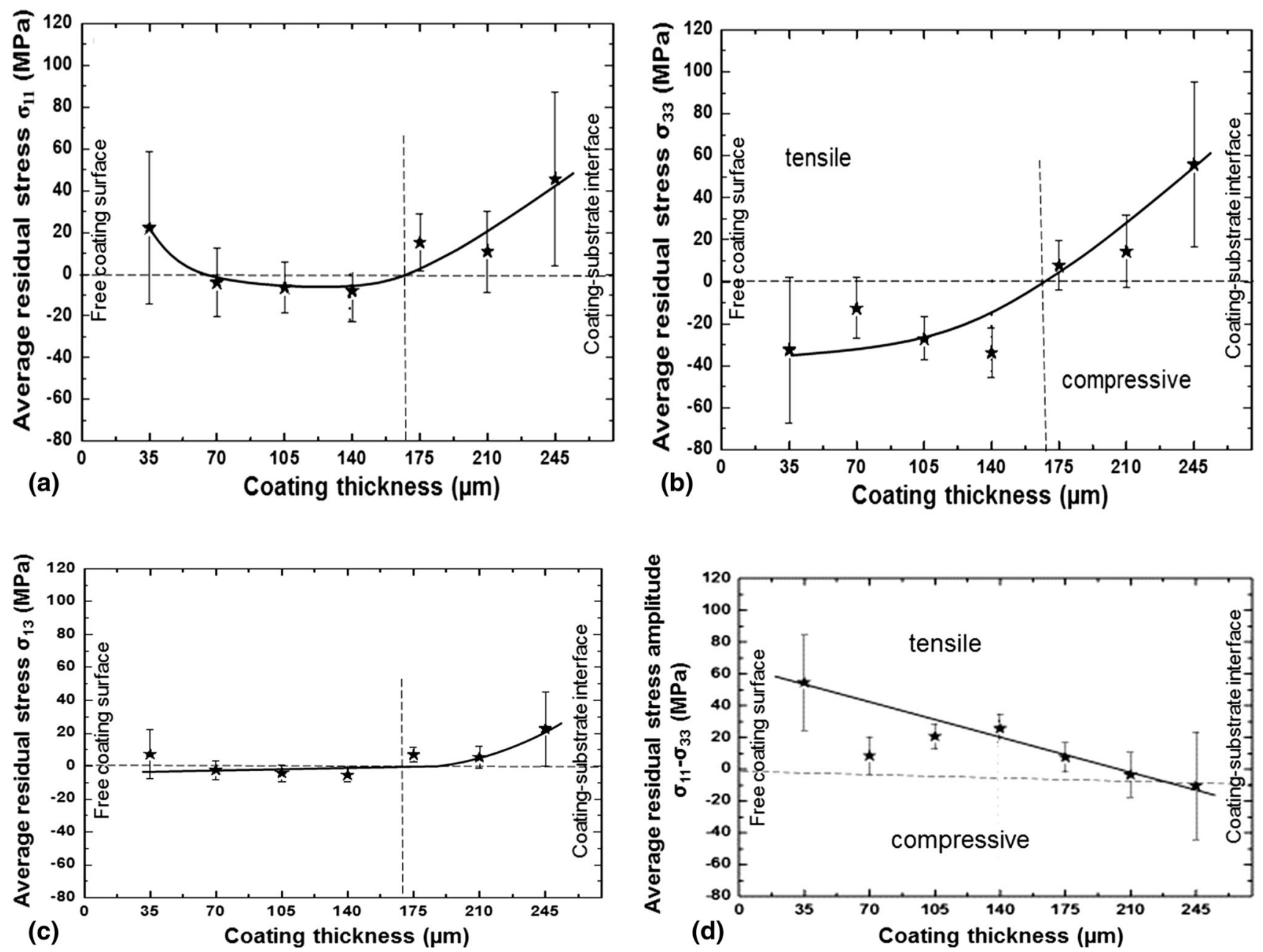

Fig. 15 Distribution of the principal Cauchy stress tensor components $\sigma_{11}$ (a) and $\sigma_{33}$ (b) as well as the shear stress tensor component $\sigma_{13}(\mathrm{c})$ and the residual stress amplitude $\sigma_{11}-\sigma_{33}(\mathrm{~d})$ as functions of the thickness of an atmospheric plasma-sprayed hydroxylapatite coating deposited on a Ti6A14V substrate. The data were averaged over three different measurement positions. The vertical dotted lines mark the position at which the residual stress changes sign (Ref 112) ( With permission by Elsevier)

the influence of surface topography including microroughness and nanostructures on the osseointegration of spinal implants.

Along similar lines, in a recent review on bioactive coatings for implants Zhang et al. (Ref 143) discussed the effect of surface micro-roughness on both osteoblast adhesion and differentiation. Osteoblast-like cells grown on moderately rough titanium surfaces $\left(4<R_{\mathrm{a}}<7 \mu \mathrm{m}\right)$ showed reduced proliferation but enhanced osteogenic differentiation expressed through upregulation of ALP and osteocalcin levels (for example Ref 144). In addition, micro-roughened surfaces inhibit osteoclast activity by upregulating RANKL (receptor activator of nuclear factor kappa-B ligand) and decoy receptor osteoprotegerin (OPG) on osteoblasts. At present, implants used in clinical practice often possess micro-pitted surfaces produced by various techniques including grit blasting, acid etching, plasma spraying, or laser treatment (Ref 145). These micro-textured implant surfaces show enhanced osseointegration compared to smooth implants (Ref 146).
In contrast to some findings reported above, nano-scale surface topography with roughness $<100 \mathrm{~nm}$ appears to have a positive effect on both osteoblast adhesion and proliferation, with cells showing enhanced tendency of spreading and improved filipodial extensions. This is presumably caused by easy attachment of collagen I fibrils and nano-crystalline whisker-like hydroxylapatite crystals with lengths ranging from 50 to $300 \mathrm{~nm}$ and width of 0.5 $5 \mathrm{~nm}$ to such nano-scaled coating depressions. The underlying mechanism of the enhanced cell adhesion is likely related to increased protein adsorption on nanoscaled surfaces (Ref 143).

\subsection{Adhesive and Cohesive Strengths}

In addition to porosity and surface roughness, the mechanical performance of thermally sprayed hydroxylapatite coatings is largely determined by the quality of their adhesion to the metallic implant surface. The degree of adhesion between coating and bone can be determined 
from retrieved orthopedic implants (see, for example, Ref $147,155)$. From these studies, it appears that the clinical success of HA-coated implants is not only the result of sufficient adhesion of the coating to the implant material, but in addition depends on many other factors including the skill of the surgeon to properly place the implant, the health and quantity of the cortical bone bed, and the age and physical condition of the patient.

Whereas in the past it was generally assumed that the sole contributor to adhesion is mechanical interlocking of the solidified particle splats with asperities of the roughened substrate surface, today chemisorption and epitaxial/topotaxial processes are considered important mechanisms contributing to coating adhesion (Ref 148).

Consequently, the adhesion of coatings will be controlled by three mechanisms:

- Mechanical anchorage in which surface roughness plays an overriding role. The molten droplets impinging at the surface of the substrate must have sufficient plasticity, high impact velocity, low viscosity, and good wettability. The adhesion strength of a ceramic coating is in many cases a linear function of the average surface roughness, $R_{\mathrm{a}}$, deliberately produced by grit blasting or laser-induced micro-roughening. Some research results suggest that the true influencing parameter appears to be the variation of the fractal dimension of the surface roughness (Ref 139).

- Physical adhesion controlled by diffusive bonding, whereby the thermal diffusivity increases with increasing contact temperature according to Fourier's law. This type of adhesion can be maximized by substrate preheating. Because of the small diffusion depth (produced by rapid solidification), the diffusive adhesion generally plays only a minor role as an adhesion mechanism (Ref 134).

- Chemical adhesion that can be engineered by adjusting the contact diffusivities. Thin reaction layers may form that improve the adhesion on a molecular scale by creating a true metallurgical bond. Epitaxially/topotaxially coordinated layers may also play a role as suggested by Filiaggi et al. (Ref 149) and Webster et al. (Ref 150).In more detail, adhesion mechanisms can be classified as 'micro-bonding' and 'macro-bonding.' Micro-bonding refers to the bonding effective along very small surface areas, the size of an individual particle splat. Macro-bonding refers to areas much larger by 10 to 100 times. Macro-bonding relates to the macroscopic roughness produced by threading and grooving methods or by blasting with extremely coarse grit (Ref 134).

Methods to estimate adhesion and/or cohesion strengths of HA coatings include standard tests such as the tensile pull test according to ASTM C633-13, the modified peel test according to ASTM D3167-10, and the diamondpoint scratch test according to ASTM C1624-05 designations. In addition, several custom-designed tests are being applied, including ultrasonic C-scan (Ref 134, 151, 152) and laser shock adhesion tests (LASAT, Ref 153).

Generally, the adhesion of plasma-sprayed hydroxylapatite layers to the implant surface was found to be notoriously weak (Ref 154, 155). This is frequently in contrast to the desired rather high value in excess of $35 \mathrm{MPa}$ (Ref 79, Table 1). In recognition of this problem, the ISO norm relaxed this value to at least $15 \mathrm{MPa}$ (Ref 80 , Table 1). While it is still almost generally accepted that the adhesion mechanism involves mechanical clamping of the coating to asperities of the roughened implant surface, there are claims that thin reaction layers of calcium dititanate $\left(\mathrm{CaTi}_{2} \mathrm{O}_{5}\right)$ or calcium titanate (perovskite, $\left.\mathrm{CaTiO}_{3}\right)$ may exist that mediate adhesion (Ref 149, 150). The control of apatite nucleation by calcium titanate surfaces (Ref 156, 157) has been explained by an epitaxial structural relationship between the (022) lattice plane of calcium titanate and the (00.1) lattice plane of hydroxylapatite (Ref 158). However, experimental evidence of such reaction layers in the as-sprayed coatings is scant (Ref 159) or absent (Ref 92, 160). Furthermore, the visualization of reaction layers by transmission electron microscopy even at high magnification (Ref 107) is inhibited by their thinness, owing to the very short diffusion path lengths of $\mathrm{Ca}^{2+}$ and $\mathrm{Ti}^{4+}$ ions, respectively, that render any potential reaction zone extremely thin.

The jury is still out on the efficacy of adhesion-mediating reaction layers. However, long-time annealing of the as-sprayed HA coatings deposited on a titanium alloy substrate beyond $900{ }^{\circ} \mathrm{C}$ resulted in the formation of an interfacial Ca-Ti oxide layer of several micrometer thickness (Ref 25, 113). To achieve higher adhesion, the degree of melting and superheating, respectively, of the HA particles in the plasma jet must be improved by an increase of the plasma enthalpy (Ref 26). However, there is an obvious conflict. High plasma enthalpy inevitably leads to increased thermal decomposition of hydroxylapatite and thus to a decrease of its resorption resistance, i.e., the in vivo longevity of the coatings. Consequently, the plasma spray parameters and the resulting microstructure of the deposited coatings need to be carefully optimized by controlling the heat transfer from the hot core of the plasma jet to the center of the powder particles (Ref 134, 161). Alternatively, other solutions have to be sought that include addition of suitable bond coats (Ref 46, 47, 159) and microstructural patterning of the substrate surface by etching or laser treatment (for example Ref 145). Moreover, coating cohesion may be improved in $\mathrm{HA}-\mathrm{ZrO}_{2}$ (Ref 20, 162, 163) and $\mathrm{HA}-\mathrm{TiO}_{2}$ composite coatings (Ref 20, 159) that show enhanced cohesion due to particle reinforcement as well as in functional gradient coatings with much reduced residual stress states (Ref 164).

\subsection{Residual Coating Stress}

Residual stress influences both mechanical properties, e.g., coating adhesion and cohesion, and chemical properties, e.g., resorption kinetics of the as-sprayed HA coatings. High residual stress levels affect the surface free 
energy of crystalline HA particles and thus tend to increase solubility (Ref 165).

There are several methods to estimate stress levels that include conventional x-ray, high-energy synchrotron radiation and neutron diffraction measurements $\left(\sin ^{2} \Psi\right.$ technique), curvature measurements (Almen-type test), the hole-drilling strain gage method, and Raman photoluminescence piezospectroscopy (see Ref 20, 134). However, stresses measured by different techniques frequently relate to different length scales so that direct comparison among the results obtained should be considered with care (see, for example, Ref 166).

The total macroscopic residual stress in plasma-sprayed HA coatings is the sum of stresses originating from quenching (also known as intrinsic stress), differential thermal mismatch of the coating and substrate as expressed by the difference in the coefficient of thermal expansion (also known as thermal stress), as well as the stress arising from volume change associated with phase transformations. The quenching stress is always tensile due to frozen-in splat contraction during cooling to ambient temperature upon deposition (Ref 167, 168). However, in ceramic coating materials the quenching stress is generally expected to be small (Ref 169) and, hence, contributes only negligibly to the total residual stress. In contrast to this, the large temperature difference experienced during cooling of superheated molten hydroxylapatite particles, and larger differences of thermal expansion coefficients between the ceramic coating material and the metallic substrate imply that thermal mismatch stresses will be very significant.

The maximum thermal stress of a plasma-sprayed coating that can be accommodated without mechanical failure can be estimated by the empirical Dietzel equation (Ref 170)

$\sigma_{\mathrm{c}}=\left\{E_{\mathrm{c}}\left(\alpha_{\mathrm{c}}-\alpha_{\mathrm{s}}\right) \Delta T /\left(1-v_{\mathrm{c}}\right)\right\}+\left\{\left[\left(1-v_{\mathrm{s}}\right) / E_{\mathrm{s}}\right] d_{\mathrm{c}} / d_{\mathrm{s}}\right\}$,

where $\alpha$ is the linear coefficient of thermal expansion, $v$ is Poisson's ratio, $E$ is Young's modulus of elasticity, $\Delta T$ is the temperature difference, and $\mathrm{d}$ is the thickness. The subscripts ' $c$ ' and ' $s$ ' refer to coating and substrate, respectively. The sign of the stresses depends on the sign of $\Delta \alpha=\left(\alpha_{c}-\alpha_{s}\right)$ : for $\alpha_{c}>\alpha_{s}$ tensile stresses develop in the coating and compressive ones in the substrate adjacent to the interface. This tensile stress can be minimized by maximizing the ratio $d_{\mathrm{s}} / d_{\mathrm{c}}$. Hence, for given values of $v$ and $E$, the coating stresses decrease with decreasing coating thickness. Since the mean coefficients of thermal expansion are $(11-12) \mathrm{ppm} /{ }^{\circ} \mathrm{C}$ for hydroxylapatite and $8.6 \mathrm{ppm} /{ }^{\circ} \mathrm{C}$ for $\mathrm{Ti} 6 \mathrm{Al} 4 \mathrm{~V}$, the theoretical residual thermal coating stress is always tensile, thus frequently leading to cracks perpendicular to the coating surface as shown in Fig. 2c. These cracks may penetrate the entire coating thickness down to the substrate surface, thereby opening up pathways for extracellular fluid to reach the first few micrometers of the deposit that consist of easily soluble ACP (Ref 107). Since dissolution of the amorphous interlayer reduces the adhesive strength and thus con- tributes strongly to premature coating delamination in vivo, crack formation must be controlled by reducing coating thickness and, hence, tensile stresses and/or by substrate preheating to reduce the temperature gradient and, hence, the difference in coefficients of thermal conductivity.

Recently, a comprehensive study was conducted to determine the stress state of plasma-sprayed HA coatings by spatially and depth-resolved diffraction methods (Ref 112). The residual stress state of the as-sprayed coatings was determined by the $\sin ^{2} \Psi$-technique, using both conventional $\mathrm{x}$-ray $(8 \mathrm{keV})$ and synchrotron radiation (11 and $100 \mathrm{keV}$ ) diffraction. Some of the results are shown in Fig. 15.

As expected from the positive sign of the $\Delta \alpha$, the principal Cauchy stress tensor components $\sigma_{11}$ and $\sigma_{33}$ are both tensile adjacent to the coating-substrate interface, but relax to zero within the first $80 \mu \mathrm{m}$ of the coating (Fig. 15a and b). Then the component $\sigma_{11}$ slightly increases with further accumulating coating thickness to become tensile again with $+20 \mathrm{MPa}$ at the free coating surface. In contrast, the tensile stress component $\sigma_{33}$ at the coating-substrate interface decreases monotonously to compressive with approximately $-30 \mathrm{MPa}$ at the free coating surface. The shear stress tensor component $\sigma_{13}$ shown in Fig. 15c is likewise tensile near the coatingsubstrate interface with $+20 \mathrm{MPa}$ and relaxes to zero within the first $80 \mu \mathrm{m}$. After this, it remains neutral for the remainder of the coating thickness up to the free coating interface. In addition, as shown in Fig. 15d the stress amplitude $\left(\sigma_{11}-\sigma_{33}\right)$ follows a strictly linear trend, increasing from zero adjacent to the coating-substrate interface and remaining tensile up to the free coating surface, with maximum tensile stress of $+60 \mathrm{MPa}$.

In conclusion, the major stress component influencing residual stress formation in the coating is $\sigma_{33}$. As expected from the empirical Dietzel equation ( $\mathrm{Eq} 5.2$ ), within the first $80 \mu \mathrm{m}$ of the deposited coating, the residual stress was found to be tensile. With further increasing coating thickness, the stress state changes to compressive. This is beneficial for coating integrity as the compressive stress counteracts crack formation and, hence, promotes coating cohesion. These findings are in general agreement with earlier work by Tsui et al. (Ref 171,172$)$ and Cofino et al. (Ref 173).

\section{Conclusion}

Deposition of hydroxylapatite coatings by atmospheric (air) plasma spraying (APS) is a mature and well-researched technique to coat metallic hip endoprosthetic and dental root implants. Hydroxylapatite-coated metallic stems of hip endoprosthetic implants are confirmed to be a reliable means to achieve their long-term in vivo survival, provided that certain requirements are met, which include appropriate design selection, sound bearing surfaces according to the patient's life expectancy, meticulous surgical technique, and adequate bone quality. However, 
despite these advantages, today we have reached a limit of the current medical practice that emphasizes replacement of tissue by a predominantly materials science-based approach. Consequently, novel developments include biologically inspired third-generation biomaterials that concentrate on repair and regeneration of damaged or lost tissue on a molecular scale, for example, through functionalization of the surfaces of bioceramics or biopolymers by osteoinductive biological agents such as BMPs or other non-collagenous proteins.

At present, conventional plasma spraying of hydroxylapatite powder particles with diameters of tens to hundreds of micrometers is still the most frequently applied and the only Food and Drug Administration (FDA)-approved method to coat implant surfaces for clinical use. However, there are shortcomings that include thermal decomposition of the feedstock during spraying, line-ofsight limitation, the difficulty to control pore sizes and porosity, and the inability to deposit coatings of less than about $20 \mu \mathrm{m}$ thickness. Nevertheless, properly applied hydroxylapatite coatings provide osteoconductive and, in concert with adsorbed osteostimulating biological agents, osteoinductive functionality that is generally attributed to their (i) chemical composition that resembles that of the inorganic component of natural bone, (ii) nano-structured surface topography, (iii) appropriate macro- and microporosity, (iv) enhanced bioadhesion, and (v) favorable dissolution kinetics.

Owing to the complexity of the interaction among numerous plasma spray parameters that influence key coating properties, during the past decades many attempts were made to optimize essential properties of osteoconductive bioceramic coatings. These properties include coating thickness, phase composition, crystallinity, porosity, micro- and nano-roughness of coating surfaces, coating adhesion and cohesion, and residual coating stresses. In particular, maintenance of phase composition at values imposed by national and international norms, and control of coating porosity by implementing novel deposition techniques such as suspension (SPS) or solution precursor plasma spraying (SPPS) are fertile development areas.

It remains to emphasize that careful engineering of hydroxylapatite coatings by appropriately adjusting and fine-tuning of plasma spray parameters will ensure that coatings can be deposited with optimum mechanical, microstructural, chemical, and biological properties.

\section{Acknowledgments}

The author gratefully acknowledges the useful comments and suggestions by Professor Jill D. Pasteris (Washington University, St. Louis, MO, USA), Professor Lech Pawłowski (Université de Limoges, Limoges, France), and Professor Christian Rey (École Nationale Supérieure des Ingénieurs en Arts Chemiques et Technologiques, ENSIACET, Toulouse, France) as well as insightful and fair criticism of two anonymous reviewers.

\section{References}

1. MedGadget, Worldwide Hip and Knee Orthopedic Surgical implant Market Shares, Trend, Growth, Strategy and Forecast 2016 to 2022. www.medgadget.com. Accessed 13 March 2016

2. R.B. Heimann (Ed.), Calcium Phosphate. Structure, Synthesis, Properties, and Applications, Nova Science Publishers Inc., New York, 2012

3. J.D. Pasteris, B. Wopenka, and E. Valsami-Jones, Bone and Tooth Mineralization: Why Apatite?, Elements, 2008, 4, p $97-$ 104

4. F.H. Albee and H.F. Morrison, Studies in Bone Growth: Triple Calcium Phosphate as a Stimulus to Osteogenesis, Ann. Surg., 1920, 71(1), p 32-39

5. J.L. Drummond, M.R. Simon, S.D. Brown, and R.J. Blattner, Degradation of Plasma-Sprayed Alumina on Metal Substrates in Physiological Media, J. Am. Ceram. Soc., 1981, 64(8), p C106C110

6. M. Jarcho, Calcium Phosphate Ceramics as Hard Tissue Prosthetics, Clin. Orthop. Rel. Res., 1981, 157, p 259-278

7. M. Jarcho, C.H. Bolen, M.B. Thomas, J. Bobick, J.F. Kay, and R.H. Doremus, Hydroxylapatite Synthesis and Characterization in Dense Polycrystalline Form, J. Mater. Sci., 1976, 11, p 20272035

8. R.Z. LeGeros, A. Chohayeb, and A. Shulman, Apatitic Calcium Phosphates: Possible Dental Restorative Materials, J. Dental Res., 1982, 61, p 343-347

9. P. Ducheyne, L.L. Hench, A. Kagan, M. Martens, J.C. Mulier, and A. Burssens, The Effect of Hydroxyapatite Impregnation on Bonding of Porous Coated Implants, J. Biomed. Mater. Res., 1980, 14, p 225-237

10. L.L. Hench and J.M. Polak, Third-Generation Biomedical Materials, Science, 2002, 295, p 1014-1017

11. H.F. Hildebrand, N. Blanchemain, G. Mayer, F. Chai, M. Lefebvre, and F. Boschin, Surface Coatings for Biological Activation and Functionalization of Medical Devices, Surf. Coat. Technol., 2006, 200, p 6318-6324

12. R.F. Service, Tissue Engineers Build New Bone, Science, 2000, 289, p 1498-1500

13. M. Navarro, A. Michiardi, O. Castaño, and J.A. Planell, Biomaterials in Orthopaedics, J. R. Soc. Interface, 2008, 5(27), p 1137-1158

14. N. Groen, M. Guvendiren, H. Rabitz, W.J. Welsh, J. Kohn, and J. de Boer, Stepping into the Omics Era: Opportunities and Challenges for Biomaterials Science, Acta Biomater., 2016, 34, p 133-142

15. C.Y. Ning, L. Zhou, and G.X. Tan, Fourth-Generation Biomedical Materials, Mater. Today, 2016, 19(1), p 2-3

16. R.B. Heimann, Transition Metal-Substituted Calcium Orthophosphates with NaSiCON Structure: A Novel Type of Bioceramics, Calcium Phosphate. Structure, Synthesis, Properties, and Applications, R.B. Heimann, Ed., Nova Science Publishers Inc., New York, 2012, p 363-379

17. C.C. Silva, M.P.F. Graça, M.A. Valente, and A.S.B. Sombra, AC and DC Conductivity Analysis of Hydroxyapatite and Titanium Calcium Phosphate Formed by Dry Ball Milling, $J$. Non Cryst. Solids, 2006, 352(9-20), p 1490-1494

18. W. Habraken, P. Habibovic, M. Epple, and M. Bohner, Calcium Phosphates in Biomedical Applications: Materials for the $\mathrm{Fu}-$ ture?, Mater. Today, 2016, 19(2), p 69-87

19. S.V. Dorozhkin, Calcium Orthophosphate Coatings, Films, and Layers, Progr. Biomater., 2012, 1, p 1-40

20. R.B. Heimann and H.D. Lehmann, Bioceramic Coatings for Medical Implants, Wiley-VCH, Weinheim, 2015

21. R.A. Surmenev, M.A. Surmeneva, and A.A. Ivanova, Significance of Calcium Phosphate Coatings for the Enhancement of New Bone Osteogenesis-A Review, Acta Biomater., 2014, 10, p 557-570

22. B. León and J.A. Jansen, Thin Calcium Phosphate Coatings for Medical Implants, Springer, New York, 2009

23. R.B. Heimann, Classic and Advanced Ceramics. From Fundamentals to Applications, Wiley-VCH, Weinheim, 2010 
24. R.B. Heimann, Structure, Properties, and Biomedical Performance of Osteoconductive Bioceramic Coatings, Surf. Coat. Technol., 2013, 233, p 27-38

25. K. De Groot, R. Geesink, C.P.A.T. Klein, and P. Serekian, Plasma-Sprayed Coatings of Hydroxyapatite, J. Biomed. Mater. Res., 1987, 21, p 1375-1381; see also R.G.T. Geesink, K. De Groot, J.G.C. Wolke, and C.P.A.T. Klein, Hip Joints with Bioactive Hydroxyapatite Coating, G.H. Buchhorn, H.G. Willert, Eds., Technical Principles, Design and Safety of Joint Implants, Hogrefe \& Huber Publishers, Seattle, 1994, p 259-275

26. R. McPherson, N. Gane, and T.J. Bastow, Structural Characterization of Plasma-Sprayed Hydroxylapatite Coatings, $J$. Mater. Sci., 1995, 6, p 327-334

27. K.A. Gross and C.C. Berndt, Thermal Processing of Hydroxyapatite for Coating Production, J. Biomed. Mater. Res., 1998, 39(4), p 580-587

28. P. Cheang and K.A. Khor, Influence of Powder Characteristics on Plasma-Sprayed Hydroxyapatite Coatings, J. Thermal Spray Technol., 1996, 5(3), p 310-316

29. S.J. Ding, C.P. Ju, and J.H. Lin, Morphology and Immersion Behavior of Plasma-Sprayed Hydroxyapatite/Bioactive Glass Coatings, J. Mater. Sci. Mater. Med., 2000, 11(3), p 183-190

30. E. Lugscheider, M. Knepper, A. Heimberg, A. Dekker, and C.J. Kirkpatrick, Cytotoxicity Investigations of Plasma Sprayed Calcium Phosphate Coatings, J. Mater. Sci. Mater. Med., 1994, 5, p 371-375

31. H. Gruner, Coating of an Implant Body, Intern. Pat. Appl. WO 1986/006617 A1, 1986

32. T.A. Vu and R.B. Heimann, Improvement of the Adhesion Strength of Plasma-Sprayed Bioceramic Coatings, DVS Berichte, 1996, 175, p 178-181

33. E. Bouyer, F. Gitzhofer, and M.I. Boulos, The Suspension Plasma Spraying of Bioceramics by Induction Plasma, J. Mater. 1997, 49(2), p 58-62

34. K.A. Gross and S. Saber-Samandari, Revealing Mechanical Properties of a Suspension Plasma Sprayed Coating with Nanoindentation, Surf. Coat. Technol., 2009, 203, p 2995-2999

35. Y. Huang, L. Song, X. Liu, Y. Xiao, Y. Wu, J. Chen, F. Wu, and Z. Gu, Hydroxylapatite Coatings Deposited by Liquid Precursor Plasma Spraying: Controlled Dense and Porous Microstructures and Osteoblastic Cell Responses, Biofabrication, 2010, 2(4), p 045003

36. Y.S. Borisov, A.L. Borisova, A.Y. Tunik, M.V. Karpets, S.G. Vojnarovich, A.N. Kislitsa, and E.K. Kuzmich-Yanchuk, Effect of Microplasma Spray Conditions on Structure, Phase Composition and Texture of Hydroxyapatite Coatings, Paton Weld. J., 2008, 9, p 4-6

37. I. Demnati, M. Parco, D. Grossin, I. Fagoaga, C. Drouet, G. Barykin, C. Combes, I. Braceras, S. Gonsalves, and C. Rey, Hydroxyapatite Coating on Titanium by a Low-Energy PlasmaSpraying Mini-Gun, Surf. Coat. Technol., 2012, 206, p 2346-2353

38. J.C. Heughebaert and G. Montel, Conversion of Amorphous Tricalcium Phosphate into Apatitic Tricalcium Phosphate, Calcif. Tissue Int., 1982, 34, p S103-S108

39. C. Combes and C. Rey, Amorphous Calcium Phosphates: Synthesis, Properties and Uses in Biomaterials, Acta Biomater. 2010, 6(9), p 3362-3378

40. S. Peroos, Z. Du, and N.H. de Leeuw, A Computer Modelling Study of the Uptake, Structure and Distribution of Carbonate Defects in Hydroxyapatite, Biomaterials, 2006, 27(9), p 21502161

41. J.D. Pasteris, C.H. Yoder, and B. Wopenka, Molecular Water in Nominally Anhydrous Carbonated Hydroxylapatite: The Key to a Better Understanding of Bone Mineral, Am. Mineral., 2014, 99, p $16-27$

42. J.E. Goldenberg, Z. Wilt, D.V. Schermerhorn, J.D. Pasteris, and C.H. Yoder, Structural Effect on Incorporated Water in Carbonated Apatites, Am. Miner., 2015, 100, p 274-280

43. C. Liu, Y. Huang, W. Shen, and J. Cui, Kinetics of Hydroxyapatite Precipitation at pH 10 and 11, Biomaterials, 2001, 22, p 301-306

44. J.D. Pasteris, A Mineralogical View of Apatite Biomaterials, Am. Miner., 2016 (in press)
45. R.B. Heimann, The Challenge and Promise of Low-Temperature Bioceramic Coatings: An Editorial, Surf. Coat. Technol., 2015. doi:10.1016/j.surfcoat.2015.12.082

46. R.B. Heimann, Design of Novel Plasma-Sprayed Hydroxyapatite-Bond Coat Bioceramic Systems, J. Thermal Spray Technol., 1999, 8(4), p 597-604

47. R.B. Heimann, Novel Approaches Towards Design and Biofunctionality of Plasma-Sprayed Osteoconductive Calcium Phosphate Coatings for Biomedical Implants: The Concept of Bond Coats, Trends in Biomaterials Research, P.J. Pannone, Ed., Nova Science Publishers Inc., New York, 2007, p 1-80

48. F.J. Martinez-Vázquez, P. Miranda, F. Guiberteau, and A. Pajares, Reinforcing Bioceramic Scaffolds with In Situ Synthesized \&-Polycaprolactone Coatings, J. Biomed. Mater. Res. A, 2013, 101(12), p 3551-3559

49. FDA, Guidance for Industry and FDA Staff-Class II Special Controls Guidance Document: Root-form Endosseous Dental Implants and Endosseous Dental Abutments. U.S. Dept. of Health and Human Services, Silver Spring, MD, 2004

50. FDA, Guidance for Industry and FDA Staff-Non-clinical Information for Femoral Stem Prostheses. U.S. Dept. of Health and Human Services, Silver Spring, MD, 2007

51. F. Fazan and P.M. Marquis, Dissolution Behavior of PlasmaSprayed Hydroxyapatite Coatings, J. Mater. Sci., 2000, 11, p 787792

52. R.B. Heimann, Thermal Spraying of Biomaterials, Surf. Coat. Technol., 2006, 201, p 2012-2019

53. R.B. Heimann, P. Itiravivong, and A. Promasa, In vivo-Untersuchungen zur Osteointegration von Hydroxylapatit-beschichteten Ti6Al4V-Implantaten mit und ohne bioinerter TitanoxidHaftvermittlerschicht, BIOmaterialien, 2004, 5(1), p 38-43

54. P. Itiravivong, A. Promasa, T. Laiprasert, T. Techapongworachai, S. Kuptniratsaikul, V. Thanakit, and R.B. Heimann, Comparison of Tissue Reaction and Osteointegration of Metal Implants Between Hydroxyapatite/Ti Alloy Coat: An Animal Experimental Study, J. Med. Assoc. Thail., 2003, 86(2), p S422S430

55. A. Herrera, J. Mateo, J. Gil-Albarova, A. Lobo Escolar, E. Ibarz, S. Gabarre, Y. Más, and L. Gracia, Cementless Hydroxyapatite Coated Hip Prostheses, BioMed. Res. Inter., 2015, 386561, $\mathrm{p} 13$

56. Y.L. Chen, T. Lin, A. Liu, M.M. Shi, B. Hu, Z.L. Shi, and S.G. Yan, Does Hydroxyapatite Coating have no Advantage over Porous Coating in Primary Total Hip Arthroplasty?. A Metaanalysis, J. Orthop. Surg. Res., 2016, 10, p 21. doi:10.1186/s13018015-0161-4

57. W.H. Harris, Traumatic Arthritis of the Hip After Dislocation and Acetabular Fractures: Treatment by Mold Arthroplasty. An End-Result Study Using a New Method of Result Evaluation, $J$. Bone Surg. Am., 1969, 51(4), p 735-755

58. W.W.R. Araujo, F.S. Teixeira, G.N. da Silva, D.M.F. Salvadori, M.C. Salvadori, and I.G. Brown, Cell Growth on 3D Microstructured Surfaces, Mater. Sci. Eng., C, 2016. doi:10.1016/ j.msec.2016.03.026

59. ASTM F1185-03, Standard Specification for Composition of Hydroxyapatite for Surgical Implants. ASTM International, West Conshohocken, PA. doi:10.1520/F1185-03R09, 2009

60. ISO 13485, Medical Devices-Quality Management Systems-Requirements for Regulatory Purposes. International Organization for Standardization, Geneva, Switzerland, 2003

61. R.B. Heimann, O. Graßmann, T. Zumbrink, and H.P. Jennissen, Biomimetic Processes During In Vitro Leaching of PlasmaSprayed Hydroxylapatite Coatings for Endoprosthetic Applications, Mater. wiss. u. Werkstofftech., 2001, 32, p 913-921

62. J. Gallo, Particle Disease: Biologic Mechanism of Periprosthetic Osteolysis in Total Hip Arthroplasty, Innate Immun., 2013, 19(2), p 213-224

63. S. Pujari-Palmer, S. Chen, S. Rubino, H. Wenig, W. Xia, H. Engqvist, L.P. Tang, and M.K. Ott, In Vivo and In Vitro Evaluation of Hydroxyapatite Nanoparticle Morphology on the Acute Inflammatory Response, Biomaterials, 2016, 90, p 1-11

64. V. Karageorgiou and D. Kaplan, Porosity of 3D Biomaterial Scaffolds and Osteogenesis, Biomaterials, 2005, 26, p 5474-5491 
65. K. Onuma, A. Oyane, T. Kokubo, G. Treboux, N. Kanzaki, and A. Ito, Precipitation Kinetics of Hydroxyapatite Revealed by the Continuous-Angle Laser Light-Scattering Technique, $J$. Phys. Chem. B, 2000, 104, p 11950-11956

66. P.F. Schofield, E. Valsami-Jones, I.R. Sneddon, J. Wilson, C.A. Kirk, N.J. Terrill, C.M. Martin, D. Lammie, and T.J. Wess, Nucleation and Growth of Nano-Apatite: Applications to Biomineralisation, Geochim. Cosmochim. Acta, 2005, 69(10), p 72

67. Q.Q. Hoang, F. Siceri, A.J. Howard, and D.S.C. Yang, Bone Recognition Mechanism of Porcine Osteocalcin from Crystal Structure, Nature, 2003, 425, p 977-980

68. Y. Shiwaku, T. Anada, H. Yamazaki, Y. Honda, S. Morimoto, K. Sasaki, and O. Suzuki, Structural, Morphological and Surface Characteristics of Two Types of Octacalcium Phosphate-Derived Fluoride-Containing Apatitic Calcium Phosphates, Acta Biomater., 2012, 8(12), p 4417-4425

69. S.I. Stupp and P.V. Braun, Molecular Manipulation of Microstructures: Biomaterials, Ceramics, and Semiconductors, Science, 1997, 277, p 1242-1248

70. Y. Zhai and F.Z. Cui, Recombinant Human-Like Collagen Directed Growth of Hydroxyapatite Nanocrystals, J. Cryst. Growth, 2006, 291(1), p 202-208

71. H. Yang and Y.J. Wang, Morphology Control of Hydroxyapatite Microcrystals: Synergistic Effects of Citrate and CTAB, Mater. Sci. Eng. C, 2016, 62, p 160-165

72. H.C. Anderson, Vesicles Associated with Calcification in the Matrix of Epiphyseal Cartilage, J. Cell Biol., 1969, 41, p 59-72

73. H. Luo, G. Xiong, C. Zhang, D. Li, Y. Zhu, R. Guo, and Y. Wan, Surface Controlled Calcium Phosphate Formation on Three-Dimensional Bacterial Cellulose-Based Nanofibers, $M a$ ter. Sci. Eng. C, 2015, 49, p 526-533

74. R.O. Hynes, Integrins: Versatility, Modulation, and Signaling in Cell Adhesion, Cell, 1992, 69(1), p 11-25

75. P. Mandracci, F. Mossano, P. Rivolo, and S. Carossa, Surface Treatments and Functional Coatings for Biocompatibility Improvement and Bacterial Adhesion Reduction in Dental Implantology, Coatings, 2016, 6(1), p 7. doi:10.3390/coa tings6010007

76. L.S. Nair and C.T. Laurencin, Polymeric Applications as Biomaterials in the Areas of Tissue Engineering and Controlled Drug Delivery, Adv. Biochem. Eng., 2006, 102, p 47-90

77. O. Rahbek, S. Overgaard, M. Lind, K. Bendix, C. Buenger, and K. Søballe, Sealing Effect of Hydroxyapatite Coating on PeriImplant Migration of Particles, J. Bone Joint Surg., 2001, 83, p 441-448

78. T.J. Callahan, J.B. Gantenberg, and B.E. Sands, Calcium Phosphate (Ca-P) Coating Draft Guidance for Preparation of Food and Drug Administration (FDA) Submissions for Orthopedic and Dental Endosseous Implants, Characterization and Performance of Calcium Phosphate Coatings for Implants, E. Horowitz and J.E. Parr, Ed., ASTM STP 1196, Philadelphia, 1994, p 185-197

79. E. Wintermantel and S.W. Ha, Biokompatible Werkstoffe und Bauweisen. Implantate für Medizin und Umwelt, Springer, Berlin, 1996

80. ISO 13779-2, Implants for Surgery-Hydroxyapatite. Part 2: Coatings of Hydroxylapatite. International Organization for Standardization, Geneva, Switzerland, 2008

81. L. Sun, C.C. Berndt, K.A. Gross, and A. Kucuk, Material Fundamentals and Clinical Performance of Plasma-Sprayed Hydroxyapatite Coatings: A Review, J. Biomed. Mater. Res. A, 2001, 58(5), p 570-592

82. R.B. Heimann, O. Graßmann, M. Hempel, R. Bucher, and M. Härting, Phase Content, Resorption Resistance and Residual Stresses of Bioceramic Coatings, Applied Mineralogy in Research, Economy, Technology, Ecology and Culture. Proc. $6^{\text {th }}$ Intern. Congress on Applied Mineralogy, ICAM 2000, Göttingen, 2000, p 155-158

83. M. Topić, T. Ntsoane, T. Hüttel, and R.B. Heimann, Microstructural Characterisation and Stress Determination in As-Plasma Sprayed and Incubated Bioconductive Hydroxyapatite Coatings, Surf. Coat. Technol., 2006, 201(6), p 3633-3641
84. E. Dörre, Hydroxylapatit-Keramik für den medizinischen Einsatz, Künstlicher Knochenersatz in der Orthopädie und Traumatologie, A. Kirgis and W. Noack, Ed., Pontenagel Press, Bochum, 1992, p 17-23

85. R.B. Heimann, N. Schürmann, and R.T. Müller, In Vitro and In Vivo Performance of Ti6Al4V Implants with Plasma-Sprayed Osteoconductive Hydroxylapatite-Bioinert Titania Bond Coat 'duplex' Systems: An Experimental Study in Sheep, J. Mater. Sci., 2004, 15, p 1945-2052

86. P. Ducheyne, S. Radin, and L. King, The Effect of Calcium Phosphate Ceramic Composition and Structure on In Vitro Behavior. I. Dissolution, J. Biomed. Mater. Res., 1993, 27, p 5-34

87. J.D. De Bruijn, Y. Bovell, and C. van Blitterswijk, Structural Arrangement at the Interface Between Plasma Sprayed Calcium Phosphates and Bone, Biomaterials, 1994, 15, p 543-550

88. E.R. Kreidler and F.A. Hummel, Phase Relations in the System SrO- $\mathrm{P}_{2} \mathrm{O}_{5}$ and the Influence of Water Vapor on the Formation of $\mathrm{Sr}_{4} \mathrm{P}_{2} \mathrm{O}_{9}$, Inorg. Chem., 1967, 6(5), p 884-891

89. P.V. Riboud, Composition et stabilité des phases a structure d'apatite dans le systeme CaO- $\mathrm{P}_{2} \mathrm{O}_{5}$-oxide de Fer- $\mathrm{H}_{2} \mathrm{O}$ a haute temperature, Ann. Chim., 1973, 8, p 381-390

90. H.C.W. Skinner, Studies in the Basic Mineralizing System, CaO$\mathrm{P}_{2} \mathrm{O}_{5}-\mathrm{H}_{2} \mathrm{O}$, Calc. Tiss. Res., 1974, 14, p 3-14

91. K.A. Gross, C.C. Berndt, P. Stephens, and R. Dinnebier, Oxyapatite in Hydroxyapatite Coatings, J. Mater. Sci., 1998, 33, p 3985-3991

92. N. Antolotti, S. Bertini, C. Fanaro, X. Ranz, C. Rey, F. Rusticchelli, and Scrivani, Interface Characterization of Different Apatite Coatings, Thermal Spray. Meeting the Challenges of the 21st Century, C. Coddet, Ed., Proc. 15th ITSC, May 25-29, 1998, Nice, France, 1998, p 1121-1126

93. O. Graßmann and R.B. Heimann, Compositional and Microstructural Changes of Engineered Plasma-Sprayed Hydroxyapatite Coatings on Ti6Al4V Substrates During Incubation in Protein-Free Simulated Body Fluid, J. Biomed. Mater. Res., 2000, 53(6), p 685-693

94. S. Dyshlovenko, B. Pateyron, L. Pawłowski, and D. Murano, Numerical Simulation of Hydroxyapatite Powder Behaviour in Plasma Jet, Surf. Coat. Technol., 2004, 179, p 110-117

95. T. Kijima and M. Tsutsumi, Preparation and Thermal Properties of Dense Polycrystalline Oxyhydroxyapatite, J. Am. Ceram. Soc., 1979, 62(9-10), p 455-560

96. Rey, C., personal communication

97. M.T. Carayon and J.L. Lacout, Study of the Ca/P Atomic Ratio of the Amorphous Phase in Plasma-Sprayed Hydroxyapatite Coatings, J. Solid State Chem., 2003, 172, p 339-350

98. R.B. Heimann, Characterization of As-Plasma-Sprayed and Incubated Hydroxyapatite Coatings with High-Resolution Techniques, Mater. wiss. u. Werkstofftech., 2009, 40(1-2), p 2330

99. M.A. Bredig, H.H. Franck, and H. Füldner, Beiträge zur Kenntnis der Kalk-Phosphorsäure-Verbindungen II, Z. Elektrochem., 1933, 39(12), p 959-969

100. J.C. Trombe, and G. Montel, Some Features of the Incorporation of Oxygen in Different Oxidation States in the Apatite Lattice. J. Inorg. Nucl. Chem., 1978, 40, p 15-21, p 27-30

101. R.B. Heimann, Tracking the Thermal Decomposition of Plasma-Sprayed Hydroxylapatite, Am. Mineral., 2015, 100, p 24192425

102. C.J. Liao, F.H. Lin, K.S. Chen, and J.S. Sun, Thermal Decomposition and Reconstitution of Hydroxyapatite in Air Atmosphere, Biomaterials, 1999, 20, p 1807-1813

103. J.C. Trombe and G. Montel, Sur la preparation de l'oxyapatite phospho-calcique, Comp. Rend. Acad. Sci. Paris, 1971, 273, p $462-465$

104. P. Hartmann, C. Jäger, J. Vogel, and K. Meyer, Solid-State NMR, X-ray Diffraction, and Infrared Characterization of Local Structure in Heat-Treated Oxyhydroxyapatite Microcrystals: An Analogy of the Thermal Deposition of Hydroxyapatite During Plasma-Spray Procedure, J. Solid State Chem., 2001, 160, p 460468

105. R.B. Heimann, H.V. Tran, and P. Hartmann, Laser-Raman and Nuclear Magnetic Resonance (NMR) Studies on Plasma- 
Sprayed Hydroxylapatite Coatings: Influence Of Bioinert Bond Coats on Phase Composition and Resorption Kinetics in Simulated Body Fluid, Mater.-wiss. u. Werkstofftechn., 2003, 34(12), p 1163-1169

106. K.A. Gross, C.C. Berndt, and H. Herman, Amorphous Phase Formation in Plasma-Sprayed Hydroxyapatite Coatings, $J$. Biomed. Mater. Res., 1998, 39(3), p 407-414

107. R.B. Heimann and R. Wirth, Formation and Transformation of Amorphous Calcium Phosphates on Titanium Alloy Surfaces During Atmospheric Plasma Spraying and Their Subsequent In Vitro Performance, Biomaterials, 2006, 27, p 823-831

108. J.M. Houben, Relations of the Adhesion of Plasma Sprayed Coatings to the Process Parameters Size, Velocity and Heat Content of the Spray Particles. Unpublished Ph.D. dissertation, Technische Universiteit Eindhoven, The Netherlands, 1988

109. R.B. Heimann and J. Kleiman, Shock-Induced Growth of Superhard Materials, Crystals. Growth, Properties, and Applications, H.C. Freyhardt, Ed., Springer, Berlin, 1988, p 1-73

110. S. Danouni, A. Abdellah el-hadj, M. Zirari, and M. Belharizi, A Thermo-Mechanical Analysis of a Particle Impact During Thermal Spraying, Appl. Surf. Sci., 2016, 371, p 213-223

111. J. Götze, H. Hildebrandt, and R.B. Heimann, Charakterisierung des in vitro-Resorptionsverhaltens von plasmagespritzten Hydroxylapatit-Schichten, BIOmaterialien, 2001, 2(1), p 54-60

112. T.P. Ntsoane, M. Topic, M. Härting, R.B. Heimann, and C. Theron, Spatial and Depth-Resolved Studies of Air PlasmaSprayed Hydroxyapatite Coatings by Means of Diffraction Techniques: Part I, Surf. Coat. Technol., 2016, 294, p 153-163

113. K.A. Gross, V. Gross, and C.C. Berndt, Thermal Analysis of Amorphous Phases in Hydroxyapatite Coatings, J. Am. Ceram. Soc., 1998, 81(1), p 106-112

114. L. Keller and W.A. Dollase, X-ray Determination of Crystalline Hydroxyapatite to Amorphous Calcium Phosphate Ratio in Plasma Sprayed Coatings, J. Biomed. Mater. Res., 2000, 49, p 244-249

115. I. Demnati, D. Grossin, C. Combes, and C. Rey, PlasmaSprayed Apatite Coatings: Review of Physical-Chemical Aspects and Their Biological Consequences, J. Med. Biol. Eng., 2014, 34(1), p 1-7

116. S. Saber-Samandari, K. Alamara, and S. Saber-Samandari, Calcium Phosphate Coatings: Morphology, Micro-Structure and Mechanical Properties, Ceram. Int., 2014, 40(1), p 563-572

117. K.A. Gross and M.R. Phillips, Identification and Mapping of the Amorphous Phase in Plasma-Sprayed Hydroxyapatite Coatings Using Scanning Cathodoluminescence Microscopy, J. Mater. Sci. Mater. Med., 1998, 9(12), p 797-802

118. K.A. Gross, M.R. Phillips, and Y. Suetsugu, Cathodoluminescence Emission for Differentiating the Degree of Carbonation in Apatites, S. Giannini, A. Moroni, Eds., Key Eng. Mater., Bioceramics, 2000, 192, p 179-182. Zürich-Uetikon, TransTech Publ

119. K. De Groot, Medical Applications of Calcium Phosphate Bioceramics, J. Ceram. Soc. Jpn, 1991, 99, p 917-926

120. P. Leali Tranquilli, A. Merolli, C. Gabbi, A. Cacchioli, and G. Gonizzi, Evaluation of Different Preparations of Plasma-Spray Hydroxyapatite Coatings on Titanium Alloy and Duplex Stainless Steel in the Rabbit, J. Mater. Sci., 1994, 5, p 345-349

121. D. De Santis, C. Guerriero, P.F. Nocini, A. Ungersbock, G. Richards, P. Gotte, and U. Armato, Adult Human Bone Cells from Jaw Bones Cultured on Plasma-Sprayed or Polished Surfaces of Titanium or Hydroxyapatite Discs, J. Mater. Sci, 1996, 7(1), p 21-28

122. R.Z. LeGeros, Calcium Phosphates in Oral Biology and Medicine, Monogr. Oral Sci, Karger, Basel, 1991

123. K. De Groot, C.P.A.T. Klein, J.G.C. Wolke, and J. de BlieckHogervorst, Plasma-Spraying of Calcium Phosphate, Handbook of Bioactive Ceramics, T. Yamamuro, L.L. Hench, and J. Wilson, Ed., CRC Press, Boca Raton, 1990, p 3-15

124. R.G. Courtney-Harris, M.V. Kayser, and S. Downes, Comparison of the Early Production of Extracellular Matrix on Dense Hydroxyapatite and Hydroxyapatite-Coated Titanium in Cell and Organ Culture, Biomaterials, 1994, 16(6), p 489-495
125. R.Z. LeGeros, I. Orly, M. Gregoire, and G. Daculsi, The BoneBiomaterials Interface, Substrate Surface Dissolution and Interfacial Biological Mineralization, J.E. Davies, Ed., University of Toronto Press, Toronto, 1991, p 76-88

126. L. Chou, B. Marek, and W.R. Wagner, Effect of Hydroxyapatite Coating Crystallinity on Biosolubility, Cell Attachment Efficiency and Proliferation In Vitro, Biomaterials, 1999, 19, p 977-985

127. B.S. Ng, I. Annergren, A.M. Soutar, K.A. Khor, and A.E. Jarfors, Characterisation of a Duplex $\mathrm{TiO}_{2} / \mathrm{CaP}$ Coating on Ti6Al4V for Hard Tissue Replacement, Biomaterials, 2005, 26(10), p 1087-1095

128. E. Park, R.A. Condrate, D.H. Lee, K. Kociba, and P.K. Gallagher, Characterization of Hydroxyapatite: Before and After Plasma Spraying, J. Mater. Sci., 2002, 13, p 211-218

129. M.S. Tung and D. Skrtic, Interfacial Properties of Hydroxyapatite, Fluorapatite and Octacalcium Phosphate. Octacalcium phosphate, L.C. Chow, and E.D. Eanes, Eds., Karger, Basel, Monogr. Oral Sci., 2001, 18, p 112-129

130. A.C. Tas, The Use of Physiological Solutions or Media in Calcium Phosphate Synthesis and Processing, Acta Biomater., 2014, 10(5), p 1771-1792

131. M.E. Fernández, C. Zorilla-Cangas, R. García-García, J.A. Ascencio, and J. Reyes-Gasga, New Model for the Hydroxyapatite-Octacalcium Phosphate Interface, Acta Cryst. B, 2003, 59, p 175-181

132. W.E. Brown, Octacalcium Phosphate and Hydroxyapatite: Crystal Structure of Octacalcium Phosphate, Nature, 1962, 196, p 1048-1050

133. A. Brangule and K.A. Gross, Importance of FTIR Spectra Deconvolution for the Analysis of Amorphous Calcium Phosphates, Mater. Sci. Eng., 2015, 77, p 012027. doi:10.1088/1757899X/77/1/012027

134. R.B. Heimann, Plasma Spray Coating. Principles and Applications. 2nd edn, Wiley, Weinheim, 2008

135. C.Y. Yang, B.C. Wang, E. Chang, and J.D. Wu, Bond Degradation at the Plasma-Sprayed HA Coating/Ti-6Al-4V Alloy Interface: An In Vitro Study, J. Mater. Sci., 1995, 6, p 258-265

136. J.E. Lemons, Biodegradation and Wear of Total Joint Replacements, Bone Implant Interface, H.U. Cameron, Ed., Mosby, St. Louis, 1994, p 307-317

137. K.S. Lew, R. Othman, K. Ishikawa, and F.Y. Yeoh, Macroporous Bioceramics: A Remarkable Material for Bone Regeneration, J. Non Cryst. Solids, 2012, 188, p 207-219

138. R. Jaworski, L. Pawłowski, C. Pierlot, F. Roudet, S. Kozerski, and F. Petit, Recent Developments in Suspension Plasma Sprayed Titanium Oxide and Hydroxyapatite Coatings, $J$. Therm. Spray Technol., 2010, 19(1-2), p 240-247

139. G. Reisel and R.B. Heimann, Correlation Between Surface Roughness of Plasma-Sprayed Chromium Oxide Coatings and Powder Grain Size Distribution: A Fractal Approach, Surf. Coat. Technol., 2004, 185, p 215-221

140. R.B. Heimann, On the Self-Affine Fractal Geometry of PlasmaSprayed Surfaces, J. Thermal Spray Technol., 2011, 20(4), p 898908

141. F. Gentile, L. Tirinato, E. Battista, F. Causa, C. Liberale, E.M. di Fabrizio, and P. Decuzzi, Cells Preferentially Grow on Rough Substrates, Biomaterials, 2010, 31(28), p 7205-7212

142. R.A. Gittens, R. Olivares-Navarrete, Z. Schwartz, and B.D. Boyan, Implant Osseointegration and the Role of Microroughness and Nanostructures: Lessons for Spine Implants, Acta Biomater., 2014, 10(8), p 3363-3371

143. B.G.X. Zhang, D.E. Myers, G.G. Wallace, M. Brandt, and P.F.M. Choong, Bioactive Coatings for Orthopaedic Implants-Recent Trends in Development of Implant Coatings, Int. J. Mol. Sci., 2014, 15(7), p 11878-11921

144. J. Lincks, B.D. Boyan, C.R. Blanchard, C.H. Lohmann, Y. Liu, D.L. Cochran, D.D. Dean, and Z. Schwartz, Response of MG63 Osteoblast-Like Cells to Titanium and Titanium Alloy is Dependent on Surface Roughness and Composition, Biomaterials, 1998, 19, p 2219-2232

145. A. Oyane, M. Kakehara, I. Sakamaki, A. Pyatenko, H. Yashiro, A. Ito, and K. Torizuka, Biomimetic Apatite Coating on Yttria- 
Stabilized Tetragonal Zirconia Utilizing Femtosecond Laser Surface Processing, Surf. Coat. Technol., 2016. doi:10.1016/ j.surfcoat.2016.03.075

146. Z. Schwartz, A.L. Raines, and B.D. Boyan, The Effect of Substrate Microtopography on Osseointegration of Titanium Implants, Comprehensive Biomaterials, P. Ducheyne, K.E. Healy, D.W. Hutmacher, D.W. Grainger, and C.J. Kirkpatrick, Ed., Elsevier, Amsterdam, 2011, p 343-352

147. K.A. Gross, B. Ben-Nissan, W.R. Walsh, and E. Swarts, Analysis of Retrieved Hydroxyapatite Coated Orthopaedic Implants, Thermal Spray. Meeting the Challenge of the 21st Century, C. Coddet, Ed., Proc. 15th Intern. Thermal Spray Conf., Nice, France, May 25-29, 1998. Vol. 2, 1133-1138

148. R. Lacombe, Adhesion Measurement Methods: Theory and Practice, CRC Taylor \& Francis, Boca Raton, 2006

149. M.J. Filiaggi, N.A. Coombs, and R.M. Pilliar, Characterization of the Interface in the Plasma-Sprayed HAp Coating/Ti-6Al-4V Implant System, J. Biomed. Mater. Res., 1991, 25, p 1211-1229

150. T.J. Webster, C. Ergun, R.H. Doremus, and W.A. Lanford, Increased Osteoblast Adhesion on Titanium-Coated Hydroxylapatite that Forms $\mathrm{CaTiO}_{3}$, J. Biomed. Mater. Res. A, 2003, 67(3), p 975-980

151. M. Ducos, B. Bossuat, S. Barradas, M. Jeandin, M. Boustie, C. Bolis, and L. Berthe, Non-Destructive Adhesion Testing of Plasma-Sprayed Coatings Using Ultrasounds and Laser Shocks, Thermal Spray 2004: Advances in Technology and Applications, C.C. Berndt, K.A. Khor, and E. Lugscheider, Ed., Proc. ITSC, Osaka, 2004, p 163-168

152. Y. Watanabe, S. Fujisawa, A. Yonezu, and X. Chen, Quantitative Evaluation of Adhesion Quality of Surface Coating by Using Pulse Laser-Induced Ultrasonic Waves, Surf. Coat. Technol., 2016, 286, p 231-238

153. V. Guipont, M. Jeandin, S. Bansard, K.A. Khor, M. Nivard, L. Berthe, J.P. Cuq-Lelandais, and M. Boustie, Bond Strength Determination of Hydroxyapatite Coatings on Ti-6Al-4V Substrates Using the Laser Shock Adhesion Test (LASAT), $J$ Biomed. Mater. Res. A, 2010, 95(4), p 1096-1104

154. C.Y. Yang, B.C. Wang, W.J. Chang, E. Chang, and J.D. Wu, Mechanical and Histological Evaluation of Cobalt-Chromium Alloy and Hydroxyapatite Plasma-Sprayed Coatings in Bone. J. Mater. Sci.: Mater. Med., 1996, 7, p.167-174

155. A.E. Porter, P. Taak, L.W. Hobbs, M.J. Coathup, G.W. Blunn, and M. Spector, Bone Bonding to Hydroxyapatite and Titanium Surfaces on Femoral Stems Retrieved from Human Subjects at Autopsy, Biomaterials, 2004, 25(21), p 5199-5208

156. T. Kokubo, H.M. Kim, and M. Kawashita, Novel Bioactive Materials with Different Mechanical Properties, Biomaterials, 2003, 24, p 2161-2175

157. N. Ohtsu, K. Saito, K. Asami, and T. Hanawa, Characterization of $\mathrm{CaTiO}_{3}$ Thin Films Prepared by Ion-Beam Assisted Deposition, Surf. Coat. Technol., 2006, 200(18/19), p 5455-5461

158. D. Wei, Y. Zhou, D. Jia, and Y. Wang, Structure of Calcium Titanate/Titania Bioceramic Composite Coatings on Titanium Alloy and Apatite Deposition on Their Surfaces in a Simulated Body Fluid, Surf. Coat. Technol., 2007, 201, p 8715-9722
159. Y.-P. Lu, M.-S. Li, S.T. Li, Z.G. Wang, and R.F. Zhu, PlasmaSprayed Hydroxyapatite + Titania Composite Bond Coat for Hydroxyapatite Coating on Titanium Substrate, Biomaterials, 2004, 25(18), p 4393-4403

160. E. Park, R.A. Condrate, D.T. Hoelzer, and G.S. Fischman, Interfacial Characterization of Plasma-Spray Coated Calcium Phosphate on Ti-6Al-4V, J. Mater. Sci., 1998, 9(11), p 643-649

161. L. Pawłowski, The Science and Engineering of Thermal Spray Coatings, 2nd ed., Wiley, Chichester, 2008

162. R. Kumar, P. Cheang, and K.A. Khor, Radio Frequency (RF) Suspension Plasma Sprayed Ultra-Fine Hydroxyapatite (HA)/ Zirconia Composite Powders, Biomaterials, 2003, 24, p 26112621

163. A. Rapacz-Kmita, A. Ślósarczyk, and Z. Paszkiewicz, Mechanical Properties of HAp-Z $\mathrm{rO}_{2}$ Composites, J. Eur. Ceram. Soc., 2006, 26(8), p 1481-1488

164. C.Y. Ning, Y.J. Wang, X.F. Chen, N.R. Zhao, J.D. Ye, and G. Wu, Mechanical Performance and Microstructural Characteristics of Plasma-Sprayed Biofunctionally Gradient $\mathrm{HA}-\mathrm{ZrO}_{2}-\mathrm{Ti}$ Coatings, Surf. Coat. Technol., 2005, 200(7), p 2403-2408

165. J.N. Sherwood and R.I. Ristic, The Influence of Mechanical Stress on the Growth and Dissolution of Crystals, Chem. Eng. Sci., 2001, 58(7), p 2267-2280

166. P.J. Withers and H.K.D.H. Bhadeshia, Residual Stress. Part 1: Measurement Techniques, Mater. Sci. Technol., 2001, 17(4), p 355-365

167. J. Matejicek and S. Sampath, Intrinsic Residual Stresses in Single Splats Produced by Thermal Spray Processes, Acta Mater., 2001, 49, p 1993-1999

168. J. Matejicek and S. Sampath, In Situ Measurement of Residual Stresses and Elastic Moduli in Thermal Sprayed Coatings. Part 1: Apparatus and Analysis, Acta Mater., 2003, 51(3), p 863-872

169. S. Kuroda and T.W. Clyne, The Quenching Stress in Thermally Sprayed Coatings, Thin Solid Films, 1991, 200, p 49-66

170. H. Salmang, H. Scholze, and R. Telle, Keramik, 7th ed., Springer, Berlin, 2007

171. Y.C. Tsui, C. Doyle, and T.W. Clyne, An Analytical Model for Predicting Residual Stresses in Progressively Deposited Coatings Part 1: Planar Geometry, Thin Solid Films, 1997, 306, p 2333

172. Y.C. Tsui, C. Doyle, and T.W. Clyne, Plasma Sprayed Hydroxyapatite Coatings on Titanium Substrate Part 1. Mechanical Properties and Residual Stress Levels, Biomaterials, 1998, 19, p 2013-2029

173. B. Cofino, P. Fogarassy, P. Millet, and A. Lodini, Thermal Residual Stresses Near the Interface Between Plasma-Sprayed Hydroxyapatite Coating and Titanium Substrate: Finite Element Analysis and Synchrotron Radiation Measurements, $J$. Biomed. Mater. Res. A, 2004, 70, p 20-27

174. B. Kasemo and J. Lausmaa, The Biomaterial-Tissue Interface and Its Analogues in Surface Science and Technology, The Bone-Biomaterials Interface, J.E. Davies, Ed., University of Toronto Press, Toronto, 1991, p 19-32

175. J.D. Pasteris, personal communication 